This is an unedited manuscript accepted for publication in the Work, Aging and Retirement. The published version might undergo minor additional editing in style and content: Burmeister, A., Hirschi, A., \& Zacher, H. (in press). Explaining age differences in the motivating potential of intergenerational contact at work. Work, Aging and Retirement.

\title{
Explaining Age Differences in the Motivating Potential of Intergenerational Contact at Work
}

Author Notes

\section{Anne Burmeister}

Assistant Professor of Human Resource Management at Rotterdam School of Management, Erasmus University, The Netherlands

\begin{abstract}
Andreas Hirschi
Professor of Work and Organizational Psychology, University of Bern, Switzerland
\end{abstract}

Hannes Zacher

Professor of Work and Organizational Psychology, University of Leipzig, Germany

Correspondence concerning this article should be addressed to Anne Burmeister, Department of Organisation and Personnel Management, Rotterdam School of Management, Erasmus University, Postbus 1738, 3000 DR Rotterdam, Netherlands. Email: burmeister@rsm.nl. 


\begin{abstract}
Understanding the effects of intergenerational contact at work is important given aging and increasingly age-diverse workforces. The aim of this research was to better understand who derives motivational benefits from intergenerational contact, and the processes by which this occurs. To do so, we adopted a motivational lens grounded in need-based theories of work motivation and lifespan development theory. We argue that the motivating effect of intergenerational contact on work engagement via sense of belonging is more pronounced for older compared to younger employees due to changes in goal priorities across the lifespan. Specifically, we posit the generativity motive and perceived remaining time at work as lifespan-related mechanisms that explain the moderating effects of age on the links between intergenerational contact and work engagement. In Study 1, a laboratory experiment with 45 younger and 45 older participants in Switzerland, we found support for a causal effect of intergenerational contact on sense of belonging. In Study 2, a three-wave field study with 560 employees in Germany, we found that sense of belonging mediated the relation between intergenerational contact and work engagement. Further, perceived remaining time at work explained the moderating effect of age on the link between sense of belonging and work engagement. By highlighting age differences in the motivating potential of intergenerational contact, we advance research on intergroup contact, employee motivation, and workforce aging.
\end{abstract}

Keywords: workforce aging; intergenerational potential; life span development theory; intergroup contact theory; need-based theories of work motivation 
Explaining Age Differences in the Motivating Potential of Intergenerational Contact at Work

Workforces in many countries are aging and becoming more age diverse due to demographic change (Boehm et al., 2014; Finkelstein et al., 2015; North, 2019). Increasing life expectancy and more flexible retirement policies (Wang \& Shultz, 2010) lead to extended working lives of many older employees. Differences in employee age are thus becoming more pronounced within organizations (Meulenaere et al., 2016). Accordingly, intergenerational contact, defined as the extent to which coworkers from different age groups interact at work (King \& Bryant, 2017), represents a relevant social characteristic of work in todays' aging and age-diverse workforces.

Research to date has clarified how intergenerational contact, as a form of intergroup contact among individuals from different age groups, can reduce negative attitudes and behavior toward other age groups (Abrams et al., 2006). Studies in the work context showed that intergenerational contact can reduce negative age stereotypes (Henry et al., 2015; Iweins et al., 2013) and buffer the effect of intergroup anxiety on discrimination in hiring (Fasbender $\&$ Wang, 2017). These findings are aligned with intergroup contact theory (Pettigrew, 1998), which argues that contact with dissimilar others improves intergroup relations. A plethora of studies showed that intergroup contact reduces prejudice and intergroup bias (Dovidio et al., 2017; Pettigrew \& Tropp, 2000; Pettigrew \& Tropp, 2008), improves outgroup attitudes (Aberson \& Haag, 2007; Harwood et al., 2017; Pettigrew et al., 2011), and leads to positive outgroup behaviors such as helping (Johnston \& Glasford, 2017). However, our understanding of the mechanisms and boundary conditions of the positive consequences of intergenerational contact at work are currently limited in two central ways.

First, existing research focused on the ways in which intergenerational contact may motivate positive intergroup relations, for example, by reducing age stereotypes and discrimination (Fasbender \& Wang, 2017; Henry et al., 2015; Iweins et al., 2013), but 
neglected the possible motivating potential of intergenerational contact for the focal individuals involved. This limited scope is surprising because we know that positive social contact at work can help employees to feel more connected, which, in turn, drives beneficial work-related outcomes such as employee motivation (Dutton \& Ragins, 2007; Ehrhardt \& Ragins, 2019; Heaphy \& Dutton, 2008).

Second, studies on outcomes of intergenerational contact in the work context have not yet focused on the role of employee age, thereby assuming that the strength of the effect of intergenerational contact does not differ between age groups. For example, Henry et al. (2015) established age differences in antecedents of intergenerational contact, more specifically in the links between opportunities for generativity and development and intergenerational contact quality, while not exploring age differences in outcomes of intergenerational contact. In the same vein, research on intergroup contact has suggested that the positive effects on interpersonal relations are universal across age groups (Pettigrew et al., 2011). Based on lifespan development theory (e.g., Baltes, 1987; Carstensen et al., 1999; Erikson, 1963), we challenge this age-blind understanding for motivational outcomes of intergenerational contact, because goal priorities and motives change across the lifespan and these changes influence socioemotional work experiences (Kooij et al., 2011; Ng \& Feldman, 2010; Rudolph, Kooij et al., 2018).

In addition, research questioning the validity of the notion of "generations" and the assertion of "generational differences" (Costanza \& Finkelstein, 2015; Rudolph, Rauvola, \& Zacher, 2018; Rudolph \& Zacher, 2017b), influenced our research in two main ways. First, research has concluded that there is insufficient empirical evidence for objective generational differences, and recommended to adopt a lifespan development perspective to understand agerelated phenomena (Rudolph \& Zacher, 2017b). We follow this advice by adopting a lifespan perspective to examine the outcomes of intergenerational contact, which we understand as interactions between employees from different age groups (see King \& Bryant, 2017). 
Second, research has noted that while we lack empirical evidence for objective generational differences, people seem to attach meaning to the term generation and might use it to construct their sense of self when interacting with others (Joshi et al., 2010; Weiss \& Lang, 2009). The subjective meaningfulness of the construct "generation" is reflected in the way we operationalize intergenerational contact as we ask participants to indicate how often they interact with coworkers "outside their generation."

To advance the literature on how to engage aging and age-diverse workforces, we adopt a motivational lens that is grounded in need-based theories of work motivation (Baumeister \& Leary, 1995; Green, Finkel et al., 2017) and lifespan development theory (Carstensen et al., 1999; Erikson, 1963). We propose that the motivating effect of intergenerational contact on work engagement occurs via an increased sense of belonging, and that this effect is more pronounced for older compared to younger employees due to changes in goal priorities across the lifespan. We focus on work engagement (i.e., a positive state of mind that is characterized by vigor, dedication, and absorption; Schaufeli et al., 2002) as an important motivational outcome, due to its positive relations with job performance, productivity, and employee well-being (Bakker \& Bal, 2010; Hakanen \& Schaufeli, 2012; Rich et al., 2010; Xanthopoulou et al., 2009).

To understand why intergenerational contact has motivating potential and to decipher the proposed link between intergenerational contact and work engagement, we herein focus on sense of belonging (Baumeister \& Leary, 1995). A sense of belonging is uniquely suited to explain the motivational outcomes of workplace interactions (Nifadkar \& Bauer, 2016; O'Reilly \& Robinson, 2009) because, according to Baumeister and Leary's theorizing, humans are fundamentally motivated by a need to belong and thus aim to feel connected. Contact with others can improve individuals' sense of belonging (i.e., achieved belongingness; Hagerty et al., 1992; Malone et al., 2012) which, in turn, makes them more 
motivated to contribute (Green, Finkel et al., 2017). We thus expect a positive link between intergenerational contact and work engagement via sense of belonging.

Further, based on lifespan development theory (Carstensen et al., 1999; Erikson, 1963), we expect that older employees derive more pronounced motivational benefits from intergenerational contact due to their increased generativity motive (i.e., individuals' concern for establishing and guiding the next generation; Erikson, 1963; Kanfer \& Ackerman, 2004) and constrained perceived remaining time at work (i.e., individuals' perception of their future in the employment context; Zacher \& Frese, 2009). We argue that the opportunity to enact generativity during intergenerational contact is more closely aligned with older (vs. younger) employees' focus on generativity, and that the experience of sense of belonging is more closely aligned with older (vs. younger) employees' focus on socioemotional goals based on their constrained (vs. more expansive) perceived remaining time at work. We thus position employee age as a relevant boundary condition and further demonstrate why older and younger employees may differ in their reactions to intergenerational contact.

With our research, we aim to make two main contributions. First, we aim to contribute to an integration of research on intergroup contact and employee motivation (Kanfer et al., 2017). We advance research on intergenerational contact by examining work engagement as a motivational outcome and thereby extend the scope of current scholarship on intergroup contact that has mainly focused on overcoming negative attitudes and behavior toward other age groups (Fasbender \& Wang, 2017; Henry et al., 2015; Iweins et al., 2013). We further decipher sense of belonging as a need-based mechanism (Baumeister \& Leary, 1995) that translates the motivating potential of intergenerational contact into work engagement. In doing so, we explicate the need-fulfilling potential of intergenerational contact as a specific workplace interaction. We thus advance research on work engagement (Bakker et al., 2008; Bakker et al., 2011) and need-based theories of work motivation (Green, Finkel et al., 2017) by specifying how intergenerational contact can fuel the energy inherent in work engagement. 
Second, we integrate the intergroup contact and lifespan development literature to examine differences across age groups. We do so by examining the moderating role of employee age in shaping the effect of intergenerational contact on work engagement. Demonstrating the different motivating potential of intergenerational contact for employees from different age groups challenges the age-blind view advanced in intergroup contact theory (Pettigrew et al., 2011) and suggests that contact domain-specific moderators (here: age) are relevant boundary conditions of specific types of intergroup contact (here: intergenerational contact). Further, we advance the workforce aging literature by simultaneously testing both positive (i.e., generativity motive) and negative age-related moderating mechanisms (i.e., perceived remaining time at work). We thus uncover the underlying mechanisms that explain why age acts as a moderator of motivational processes at work (see Bohlmann et al., 2018).

\section{Theoretical Background}

We adopt a motivational lens to further our understanding of the outcomes of intergenerational contact at work. This motivational lens is reflected in our theorizing in terms of the motivational processes that we propose to explain why intergenerational contact motivates work engagement and why employee age shapes the motivating potential of intergenerational contact. Figure 1 displays our conceptual model.

First, we draw on need-based theories of work motivation (Green, Finkel et al., 2017) to explain why intergenerational contact motivates work engagement. Need-based theories of work motivation propose that employees act because they aim to fulfill basic human needs (Latham \& Pinder, 2005), such as belonging (Baumeister \& Leary, 1995). According to Baumeister and Leary (1995), humans have a fundamental need to belong that they aim to fulfill through meaningful interactions with others. More recent work echoed the "motivational power of need fulfillment experiences" (Green, Finkel et al., 2017, p. 3), and emphasized that interactions with others at work are central for need fulfillment and 
subsequent work engagement. Based on these insights, we propose that sense of belonging (i.e., experienced belonging) explains why intergenerational contact motivates work engagement. Research on intergenerational interactions outside of the workplace already indicated that both older adults and adolescents derive motivational benefits from interacting with each other (Kessler \& Staudinger, 2007; Tabuchi \& Miura, 2018).

Second, we build on lifespan development theory (Carstensen et al., 1999; Erikson, 1963) to propose that the motivating potential of intergenerational contact is more pronounced for older compared to younger employees due to lifespan-related changes in goal priorities. Lifespan development theories describe aging as a continuous and multidirectional process in which resource gains and losses go hand-in-hand, such that different psychological characteristics might either remain stable, increase, or decrease across the lifespan (Baltes, 1987). Two central psychological characteristics that are affected by the aging process are the generativity motive and perceptions of remaining time (Carstensen, 2006; Erikson, 1963). On average, the generativity motive increases with age (Kooij et al., 2011), while perceived remaining time at work decreases with age (Henry et al., 2017; Rudolph, Kooij et al., 2018). These lifespan-related changes in motives and perceptions of time influence individuals' goal priorities and interactions with their social environment. For example, investing time and effort into gaining knowledge and resources might be motivating for younger individuals who have an expansive future time perspective and can reap the benefits of their present investment in the future. Older workers however, with a constrained future time perspective, are more focused on enjoying the present and creating their legacy through enacting generativity in social relationships and sharing their knowledge with future generations (Hertel \& Zacher, 2018; Lang \& Carstensen, 2002).

\section{Hypotheses Development}

\section{The Effect of Intergenerational Contact on Work Engagement via Sense of Belonging}


Research shows that contact is beneficial for employees' sense of belonging. First, contact provides an opportunity to share and receive valued resources. Employees appreciate the opportunity to acquire resources, such as knowledge and skills, through social interactions (Kilduff \& Brass, 2010; Lang \& Carstensen, 2002). Further, employees enjoy contributing to others and being needed by others can lead to a sense of belonging (Hagerty et al., 1996). Second, contact enables employees to connect and relate to others and widen their social support network, which can fulfill their need for belonging (Ilies et al., 2018; Reich \& Hershcovis, 2011; Wang \& Eccles, 2012).

Intergenerational contact may be particularly beneficial for improving employees' sense of belonging. First, older and younger coworkers are highly effective in providing each other with support and assistance because their experiences, networks, and insights are nonredundant and often complementary (Burmeister et al., 2020; Gerpott et al., 2017; Li et al., in press). Older workers can help younger workers to understand how to interact with others in more meaningful ways to build long-lasting relationships (Gerpott et al., 2017), while younger workers can help older workers by demonstrating how to handle complexity and connect with a wider range of different people based on their larger social networks ( $\mathrm{Li}$ et al., in press). Intergenerational contact thus provides access to resources and support that may otherwise be difficult to obtain because similarly aged peers are less likely possess these resources, and thereby facilitates a sense of belonging. Second, intergenerational contact provides employees with the opportunity to interact with an extended network of social contacts that supports and validates them (Shumaker \& Brownell, 1984). These social interactions with dissimilar others may be perceived as signals of acceptance by a broad range of people and can lead to a sense of belonging because of the diversification of one's support network (Kunstman et al., 2013; Sandstrom \& Dunn, 2014). In addition, employees who experience cooperative intergenerational interactions might feel more connected to others because they are treated as insiders by a different age group and are included in information flows they previously did not 
have access to (see Shore et al., 2011; Shore et al., 2018). We thus expect that intergenerational contact leads to sense of belonging because employees feel connected through the exchange of valuable and non-redundant resources and perceive cooperative interactions with dissimilar others as signals of social acceptance (Keyes, 2002; Vondras et al., 2008).

Hypothesis 1a: Intergenerational contact is positively related to sense of belonging. In turn, sense of belonging is positively related to work engagement. Sense of belonging may be particularly influential for work engagement because social interactions strongly influence employees' conceptualization of their work experience (Grant \& Parker, 2009; Wrzesniewski et al., 2003). Specifically, feeling connected through social interactions can elicit positive emotional states that are energizing (Ehrhardt \& Ragins, 2019; Green, Finkel et al., 2017). Accordingly, sense of belonging has been shown to motivate employees' work engagement, because employees derive intrinsic motivation from feeling connected to others (Kovjanic et al., 2013). As a result, employees' absorption in their work and the vigor and dedication with which they conduct their work are more pronounced (Bakker et al., 2008; Bakker \& Demerouti, 2007; Deci \& Ryan, 1985; van den Broeck et al., 2008).

Hypothesis $1 b$ : Sense of belonging is positively related to work engagement.

In line with our assumption that intergenerational contact has an indirect positive relation with work engagement via sense of belonging, research has verified the link between genuine interpersonal connections and enjoyment of tasks in a variety of contexts, ranging from education, to sport, health care, and the work domain (Christian et al., 2011; Gagné \& Deci, 2005). Research has further demonstrated that this positive effect can be explained by sense of belonging (Knight et al., 2017; van den Broeck et al., 2008; Wang \& Eccles, 2012).

Hypothesis 1c: Sense of belonging mediates the relation between intergenerational contact and work engagement. 


\section{Age and Generativity Motive as Moderators}

To explain age differences in the strength of the link between intergenerational contact and sense of belonging, we hypothesize that age has an indirect moderating effect through the generativity motive.

First, we assume that age is positively related to the generativity motive. According to Erikson (1963), generativity as the concern for guiding and establishing the next generation should initially emerge in middle adulthood (i.e., around 40 years) as a distinct state in a person's psychosocial development. While generativity can also be enacted by younger individuals (e.g., young parents caring for their children, young teachers guiding their students; McAdams \& St. Aubin, 1998), a positive association between age and the generativity motive is expected, because relevant experience and opportunities increase with age (McAdams et al., 1993). Empirical evidence supports this assumption as older compared to younger employees tend to have a higher generativity motive (Kooij et al., 2011; Zacher et al., 2011), appreciate jobs more in which they have the opportunity to pass on knowledge to younger coworkers (Mor-Barak, 1995), and engage in more helping and mentoring behavior of younger coworkers (Garcia et al., 2018). Furthermore, having the opportunity to enact generativity represents one of the reason why older employees work even beyond retirement age (Zhan et al., 2015).

Hypothesis 2a: Age is positively associated with generativity motive.

Second, we propose that the generativity motive is an underlying mechanism that explains the moderating effect of age on the relation between intergenerational contact and sense of belonging. Specifically, we expect that older employees derive more pronounced sense of belonging from intergenerational contact, because of the alignment of the generative opportunities during intergenerational contact and older workers' generativity motive. During intergenerational contact, both older and younger coworkers have the opportunity to influence each other by exchanging their knowledge and experiences and by providing emotional and 
social support (Burmeister \& Deller, 2016; Gerpott et al., 2017; Tempest, 2003). These interactions during intergenerational contact are more likely to improve the sense of belonging of older employees because they can act upon their generativity motive by supporting younger employees (Lang \& Carstensen, 2002). Accordingly, the generative opportunities inherent in intergenerational contact are better aligned with older employees' goal priorities (Lang \& Carstensen, 2002). This complementary fit between what employees prioritize and wat they receive from their workplace relationships has been shown to lead to the experience of relational attachment (Ehrhardt \& Ragins, 2019). The generativity motive thus explains why older (vs. younger) employees experience a stronger sense of belonging because of intergenerational contact.

Hypothesis $2 b$ : Generativity motive moderates the positive effect of intergenerational contact on sense of belonging; the positive effect of intergenerational contact on sense of belonging is stronger for people higher in generativity motive than for those lower in generativity motive.

Hypothesis 2c: Age has an indirect moderation effect (through the generativity motive) on the effect of intergenerational contact on sense of belonging; the positive effect of intergenerational contact on belonging is stronger for older compared to younger employees.

\section{Age and Perceived Remaining Time at Work as Moderators}

To explain age differences in the strength of the link between sense of belonging and work engagement, we hypothesize that age has an indirect moderating effect through perceived remaining time at work.

First, we argue that age is negatively related to perceived remaining time at work because younger individuals tend to perceive time as more expansive in terms of "time since birth," while older individuals are more likely to view time as constrained in terms of "time left in life." Perceived remaining time at work represents a sub-dimension of occupational 
future time perspective (Zacher \& Frese, 2009), and closely reflects Carstensen's concept of future time perspective, applied to the employment context (Henry et al., 2017). In line with our argument, recent meta-analytical evidence showed that age is strongly and negatively associated with perceived remaining time at work (Kooij et al., 2018; Rudolph, Kooij et al., 2018). Further, as most adults exit the workforce between 60 and 70 years of age, moving closer to the retirement stage should go hand in hand with decreases in perceived remaining time at work (Kooij \& Zacher, 2016). Hence, we expect older employees to perceive their remaining time at work to be more constrained compared to younger employees.

Hypothesis 3a: Age is negatively associated with perceived remaining time at work. Second, we argue that perceived remaining time at work is the mechanism underlying the moderating effect of age on the link between sense of belonging and work engagement. Individuals' perception of remaining time influences their goal priorities, such that people with more constrained future time perspective tend to focus on positive socioemotional experiences, while people with a more expansive future time perspective tend to be more concerned with knowledge accumulation and personal development (Carstensen et al., 1999; Carstensen, 2006; Lang \& Carstensen, 2002). This effect is also noticeable in organizations in which older employees' remaining occupational time until retirement directs their attention to socioemotional goals (Henry et al., 2017; Zacher \& Frese, 2009; Zacher \& Griffin, 2015). Feeling connected to others at work represents a pleasant socioemotional experience and is therefore closely aligned with older employees' goal priorities. Close alignment between employees' work experience and their goal priorities can contribute to more favorable attitudes and behavior at work (Greguras \& Diefendorff, 2009). For example, Linz (2004) found that, compared to younger workers, older workers attached greater importance to feeling respected by their coworkers in terms of their motivation at work. This finding is echoed by recent research on work motivation, which demonstrated that employees, who have their specific needs met by their work relationships, experience stronger organizational 
attachment, more desirable work attitudes, and more positive psychological states (Ehrhardt \& Ragins, 2019). Therefore, sense of belonging should lead to stronger work engagement for employees with more constrained perceived remaining time at work.

Hypothesis 3b: Perceived remaining time at work moderates the positive effect of sense of belonging on work engagement; the positive effect of sense of belonging on work engagement is stronger for employees with more constrained perceived remaining time at work than for those with more expansive perceived remaining time at work.

Hypothesis 3c: Age has an indirect moderation effect (through perceived remaining time at work) on the positive effect of sense of belonging on work engagement; the positive effect of sense of belonging on work engagement is stronger for older compared to younger employees.

\section{Overview of Studies}

We devised two empirical studies to test our hypotheses. In combining an experimental study (Study 1) with a time-lagged field study (Study 2), we aimed to maximize both internal and external validity. In Study 1, we focused on the first part of the conceptual model (see Figure 1). We aimed to confirm the causal link between intergenerational contact and sense of belonging, moderated by age via generativity motive (i.e., testing Hypothesis 1a and Hypotheses 2a-2c). In doing so, we also aimed to address possible questions about the extent to which the effect on sense of belonging is driven by the specific nature of intergenerational contact compared to other types of workplace contact, such as intragenerational contact. As a result, we designed an experimental study in which we compared the effect of intergenerational contact on sense of belonging to an active control condition as the reference group as well as to an intragenerational contact group. In Study 2, a time-lagged field study with three measurement waves, we examined our complete conceptual model. We tested how sense of belonging mediates the effect of intergenerational contact on 
work engagement and how age, mediated by generativity motive and perceived remaining time at work, moderates this effect.

\section{Study 1}

\section{Methods}

\section{Procedure}

Five undergraduate psychology students recruited the participants for this study in the German-speaking part of Switzerland. Overall, 90 participants were recruited. Students recruited 90 participants overall of which 45 people were younger than 33, and 45 people were older than 41 . For the older age group, the students recruited employees of the university from a wide range of specializations (e.g., secretaries, scientific personnel, information technology specialists). For the younger age group, they recruited students of the university from a wide range of study backgrounds (e.g., psychology, education, and economics).

While the age-based cut-offs are arbitrary (Ng \& Feldman, 2010; Rudolph \& Zacher, 2017a), they enabled us to create different age-based experimental groups (i.e., intergenerational and intragenerational) and intergenerational pairs with an age difference around 10 years (see Burmeister, Fasbender, \& Deller, 2018). This minimum gap precludes contact between members of closely adjacent birth years with potentially minimal age difference (e.g., between 37 and 40 years). Within the young $(n=45)$ and the old $(n=45)$ age groups, participants were randomly assigned to the three conditions: intergenerational contact $(n=30)$, intragenerational contact $(n=30)$, and no contact $(n=30)$. We then randomly created 15 age-diverse pairs (i.e., intergenerational; young-old) and 15 same-age pairs (i.e., intragenerational; young-young or old—old) to establish the intergenerational condition and the intragenerational condition, respectively. The 15 same-age pairs consisted of seven oldold pairs and eight young - young pairs. The 30 individuals in the control condition did not interact with another individual during the intervention. However, to facilitate the data analysis of the nested data (i.e., individuals nested in intergenerational or intragenerational 
pairs), we randomly assigned the 30 individuals in the control condition to pseudo pairs as well (i.e., intergenerational; young-old).

Participants were invited to the laboratory at a specific date and time and were told that they are participating in a study on work behavior. Upon arrival in the laboratory, participants were greeted by one of the students and placed at a computer. Here, they received written information about the study's procedure. First, participants filled in the preintervention survey that included the measure for belonging. Second, participants were asked to engage in an activity for 15 minutes. More specifically, they were asked to solve a crossword puzzle with twelve words. After solving the crossword puzzle, they were also asked to reflect on the resulting solution word, which was "career aspiration." To facilitate the reflection, participants could use three questions that were displayed at the door of the experimental room (e.g., what would be your dream job and why?). The crossword puzzle was created for the purpose of this study with a publicly available online software and had an average degree of difficulty. In the intergenerational contact condition, one participant of the younger age group and one participant of the older age group solved the crossword puzzle together and jointly reflected on the solution. In the intragenerational condition, the two participants were either both from the younger age group or both from the older age group. In the active control condition, participants solved the crossword puzzle on their own, and reflected on the solution in writing. To compare the effect of intergenerational contact to intragenerational contact and the control group, we created two dummy-coded variables for intergenerational and intragenerational contact in our analysis. In the intergenerational contact group, the average age difference was 27.60 years $(S D=6.82)$, and the age difference in the intragenerational contact group was 5.93 years $(S D=3.65)$. Third, after 15 minutes, one of the students entered the room to end the activity, place the participants at a computer, and ask them to fill in the post-intervention survey that included the measure of belonging and 
demographics. Before leaving the laboratory, one of the students provided the participants with an oral and a written debriefing about the study's purpose.

\section{Participants}

The 90 participants were German-speaking employees and students of a university in Switzerland. On average, participants in the younger age group were 24.47 years old $(S D=$ 3.25, $\operatorname{Min}=19, \operatorname{Max}=32)$, and participants in the older age group were 51.02 years old $(S D=$ 6.15 , Min $=42, \operatorname{Max}=62$ ). Overall, $65 \%$ of the participants were female. Of the participants, $13 \%$ had a PhD, $36 \%$ held a bachelor's or master's degree, $19 \%$ had finished vocational training, and the remaining 33\% had finished high school. They had, on average, 15.68 years of work experience $(S D=13.14$, Min $=0, \operatorname{Max}=44)$. To thank them for their participation, participants could participate in a raffle for gift vouchers.

\section{Measures}

We applied all measures in German and used a translation-back-translation procedure to translate the original English items into German.

Sense of Belonging. We measured sense of belonging before and after the manipulation with the 6-item scale by Malone et al. (2012). We asked participants to indicate their momentary agreement or disagreement on a 7-point scale. A sample item is "Right now, I have a sense of belonging." Cronbach's alpha values were .95 (pre-intervention) and .93 (post-intervention).

Employee Age. We asked participants to indicate their chronological age in years in the post-intervention questionnaire. To facilitate the interpretation of the unstandardized coefficient for chronological age in comparison to the other unstandardized coefficients in our analysis, we rescaled employee age by factor 10 (Gielnik et al., 2018).

Generativity Motive. We measured generativity motive with the three-item scale by Kooij and Van De Voorde (2011). A sample item is "How important is the chance to teach 
and train others for you?" ( $1=$ Not important at all, $7=$ Very important $)$. Cronbach's alpha was .92.

\section{Analytical Strategy}

To test our hypotheses, we ran one overall path analytic model using a between-person approach. All analyses were performed using the package lavaan in $\mathrm{R}$ using maximum likelihood estimator (R Core Team, 2017). Our experimental data was hierarchically structured because participants were nested in dyads. To generate unbiased estimated and standard errors, we thus performed hierarchical regression analysis (Bryk \& Raudenbush, 1992; Klein \& Kozlowski, 2000; Raudenbush \& Bryk, 2002). We grand-mean centered all variables except the dependent variable, and we used the multilevel option in the package lavaan in $R$ (R Core Team, 2017) to estimate a multilevel path analytic model. We controlled for pre-intervention sense of belonging, which means that the regression coefficients can be interpreted as change in sense of belonging from before to after the intervention. To test Hypotheses 2c, which specified a mediated moderation effect of age via generativity motive, we estimated an indirect effect in terms of a Type II Mediated Moderation (Gielnik et al., 2018; Wang et al., 2015). More specifically, we calculated the mediated moderation of age through generativity motive by multiplying the effect of age on generativity motive with the interaction effect between generativity motive and intergenerational contact (for an example of equations and Mplus code, please see Gielnik et al., 2018). To test the significance of this indirect effect, we estimated 95 percent bias-corrected bootstrap confidence intervals (CIs) to account for potential deviations from normality of the parameter estimates (Preacher \& Hayes, 2008).

\section{Results}

Table 1 displays the means, standard deviations, and intercorrelations of the study variables.

\section{Preliminary Analysis}


Before testing our hypotheses, we tested for pre-intervention differences to identify factors that need to be controlled because they might affect the proposed causal effect of the intergenerational contact intervention. We tested pre-intervention differences using ANOVA by comparing the three groups (i.e., control group, intragenerational contact group, intergenerational contact group) on focal study variables and demographic differences. We found no differences on the focal variables pre-intervention sense of belonging, $F(2,87)=$ $0.21, p=.815 ;$ age $, F(2,87)=0.28, p=.760 ;$ and generativity motive, $F(2,87)=2.01, p=$ .141. In addition, we found no differences on the demographic characteristics education $(1=$ primary school, 2 = secondary school, 3 = vocational education, $4=$ bachelor $/$ master degree, 5 $=\mathrm{PhD} / \mathrm{MBA}), F(2,83)=0.31, p=.737$; dyadic educational difference $(0=$ no dyadic educational difference, $1=$ dyadic educational difference), $F(2,79)=0.52, p=.597$; and gender, $F(2,85)=0.17, p=.847$. However, we found a significant difference across groups on dyadic gender composition $(0=$ same gender dyad, $1=$ mixed gender dyad $), F(2,83)=3.58, p$ $=.032$. We thus controlled for dyadic gender composition in our hypothesis tests.

\section{Hypothesis Tests}

As displayed in Table 2 and in support of Hypothesis 1a, we found that intergenerational contact had a positive effect on sense of belonging, while controlling for pre-intervention sense of belonging and intragenerational contact. In line with Hypothesis $2 \mathrm{a}$, age was positively and significantly related to generativity motive. However, Hypothesis $2 \mathrm{~b}$ was not supported because the moderating effect of generativity motive on the effect of intergenerational contact on sense of belonging was sizeable but non-significant. As a result, the indirect moderation effect of age on the relation between intergenerational contact and sense of belonging through generativity motive was not significant (indirect effect $=.07, S E=$ $.05, p=.161)$. Hypothesis $2 \mathrm{c}$ was therefore not supported.

\section{Robustness Checks}


To test the independence of our findings from the data analytical approach, we estimated the same model using hierarchical linear modeling with the package lmer in $R$ (instead of path analysis with the package lavaan in R). To test the significance of the indirect effects, we used parametric bootstrapping with Monte Carlo method. Results of the multilevel path analytic model estimated with lavaan and the hierarchical regression model estimated with lmer led to the same interpretation of results.

\section{Discussion}

The results of Study 1 provide support for our argument that intergenerational contact helps people to feel more connected to others. By comparing this effect to an intrageneration contact group, our findings indicate that the specific nature of intergenerational contact might be particularly beneficial. However, we did not find support for our argument that older compared to younger people feel more connected to others after intergenerational contact because of their higher generativity motive. This non-significant finding, might be due to the our relatively small sample size, which makes the detection of interaction effects more difficult (Shieh, 2009). The non-significant interaction effect might thus potentially become significant in a research design with a larger sample and more power. Study 2, which tests the complete conceptual model, also aims to further investigate the moderation effect of generativity motive using a larger sample.

\section{Study 2}

\section{Method}

\section{Procedure}

We conducted a time-lagged study with three measurement waves, each three months apart, over a total period of six months in Germany. We commissioned an online research company that manages a large research-only consumer and business panel to collect the data for this study. The ISO 26362 certified panel company compensated the participants for their time (between $€ 3.01$ for participation in one wave only and $€ 9.24$ for participation in all three 
waves). At first, 5,083 invitations were sent to potential participants in the panel company's database, who were German speaking and at least part-time employed (i.e., at least 20 hours per week). In total, 1,026 people clicked on the link of the first questionnaire. Of these people, 560 participants provided data on the study variables at Time 1. All participants who had provided data at Time 1 were invited to participate in Waves 2 and 3 . Of the 560 participants, $53 \%(n=297)$ provided data at all three time points, $28 \%(n=157)$ provided data at two time points, and 19\% $(n=106)$ provided data at the first time point only.

\section{Participants}

Participants were on average 46.74 years old $(S D=10.89$, Min $=19$, Max $=72)$, and $41.29 \%$ were female. They worked in diverse industries, including professional services (29\%), manufacturing (25\%), public sector (14\%), health sector (11\%), trade (10\%), insurance and banking (6\%), and education (5\%). They had an average organizational tenure of 14.61 years $(S D=11.40)$ and worked 38.93 hours per week $(S D=4.12)$.

\section{Measures}

We applied all measures in German and used a translation-back-translation procedure to translate the original English items into German.

Intergenerational Contact. At Time 1, we measured intergenerational contact with the four-item intergenerational contact frequency scale by King and Bryant (2017). The scale was designed to capture the frequency of "cooperative" and informal contact between older and younger coworkers (King \& Bryant, 2017, p. 128). The item stem "How often do you..." is followed by the four items: “...have conversations with co-workers outside your generation?”, “...have conversations with co-workers outside your generation relating to things other than work?”, “...talk with co-workers outside your generation about your personal lives?”, and “...eat meals with co-workers outside your generation during the workday?" $(1=$ Never, 7 = Very often $)$. We instructed participants to refer to interactions with coworkers who belonged to a generation "that was not their own" in answering the items 
(Henry et al., 2015, p. 247). As there is no exact definition of the term "generations" and as age-based cut-off values to identify generations are arbitrary (Rudolph \& Zacher, 2017b), we did not assign participants to a generational group based on their age before answering the items. Instead, participants identified themselves which of their interactions they perceived as intergenerational, based on the notion that the generational concept is meaningful for workers in constructing their sense of self (Joshi et al., 2010; Weiss \& Lang, 2009). Employees can thus be expected to have a working concept of the term "generations" and be able to identify other's generational membership relative to themselves. As suggested by Henry et al. (2015), when thinking about the "other generation" older workers (e.g., older than 50 years) are likely to think about contact with younger coworkers, while younger coworkers (e.g., 50 years or younger) are likely to think about contact with older coworkers.

Cronbach's alpha for the scale was .75.

Employee Age. At Time 1, we asked participants to indicate their chronological age in years. To facilitate the interpretation of the unstandardized coefficient for chronological age in comparison to the other unstandardized coefficients in our analysis, we rescaled employee age by factor 10 (Gielnik et al., 2018).

Generativity Motive. At Time 1, we measured generativity motive with the same 3item scale by Kooij and Van De Voorde (2011) as in Study 1. Cronbach's alpha was .92.

Sense of Belonging. At Time 2, we measured sense of belonging with a four-item scale by Chiniara and Bentein (2016), which provides an assessment of work-specific sense of belonging. Participants were instructed to indicate how fulfilling their current work is regarding different indicators of belonging ( $1=$ Not fulfilling at all, $7=$ Completely fulfilling $)$. A sample item is "The feeling of being part of a group at work." Cronbach's alpha was .85 .

Perceived Remaining Time at Work. At Time 2, we measured perceived remaining time at work using three items from the occupational future time perspective scale by Zacher 
and Frese (2009). Perceived remaining time at work is a sub-dimension of occupational future time perspective and reflects aging-related perceptions of time left in the employment context. This operationalization closely reflects Carstensen's (e.g., Carstensen, 2006) context-free conceptualization of future time perspective, as applied to the employment context (Henry et al., 2017; Rudolph, Kooij et al., 2018). A sample item is "My occupational future seems infinite to me" ( 1 = Strongly disagree, $7=$ Strongly agree $)$. Cronbach's alpha was .86 .

Work Engagement. At Time 3, we measured work engagement with the German version of the nine-item work engagement scale (Schaufeli et al., 2006; Schaufeli \& Bakker, 2003). Participants were asked to indicate how often they feel a certain way about their job ( 1 $=$ Never, $7=$ Every working day). A sample item is "At my work, I feel bursting with energy." Cronbach's alpha was .96.

Control Variables. We followed methodological recommendations to refrain from the inclusion of control variables unless there is a meaningful theoretical rationale (Becker, 2005; Becker et al., 2016; Bernerth \& Aguinis, 2016). First, we controlled for participants' need to belong because the need to foster acceptance and belonging varies across individuals (Leary \& Kelly, 2009). Employees with a higher need to belong might react more positively to intergenerational contact and might also derive more motivational benefits from experienced belongingness. We measured need to belong at Time 1 with four items that we adapted from Chiniara and Bentein (2016). A sample item is "How important is it to you to feel part of a group at work" $(1=$ Very unimportant, $7=$ Very important $)$. Cronbach's alpha was .81 .

Second, we controlled for opportunities for social interactions at work to distinguish the effect of intergenerational contact from the general level of social interactions at work. We measured opportunities for social interactions at work at Time 1 with three items from the social support scale introduced by Morgeson and Humphrey (2006) as part of their Work Design Questionnaire (WDQ). A sample item is "I have the opportunity to meet with others in my work" $(1=$ Strongly disagree, $7=$ Strongly agree $)$. Cronbach's alpha was .74. 
THE MOTIVATING POTENTIAL OF INTERGENERATIONAL CONTACT AT WORK 24

\section{Analytical Strategy}

As in Study 1, we ran one overall path analytic model to test our hypotheses. To maintain statistical power and reduce bias, we followed methodological recommendations for handling missing data in longitudinal studies (Graham, 2009; Wang et al., 2016), and requested full information maximum likelihood estimation (Little \& Rubin, 2002; Newman, 2014). We centered all variables, except the dependent variable, prior to creating the interaction terms and conducting the analyses. To test the indirect effect of intergenerational contact on work engagement via sense of belonging as specified in Hypothesis 1c, we estimated 95 percent bias-corrected bootstrap CIs (Preacher \& Hayes, 2008). To test Hypotheses 2c and 3c, we estimated indirect effects in terms of a Type II Mediated Moderation (Gielnik et al., 2018; Wang et al., 2015), as described in Study 1.

\section{Results}

Table 3 displays the means, standard deviations, and intercorrelations of the study variables.

\section{Preliminary Analysis}

Before testing our hypotheses, we tested the empirical distinguishability of the five focal multi-item measures in our model (intergenerational contact, sense of belonging, work engagement, generativity motive, and perceived remaining time at work) using confirmatory factor analysis (CFA). The five-factor model showed an acceptable model fit $\left(\chi^{2}=783.83, d f\right.$ $=220, \mathrm{CFI}=.92, \mathrm{TLI}=.91, \mathrm{RMSEA}=.07, \mathrm{SRMR}=.06)$, and fit better than a four-factor model in which we combined sense of belonging and work engagement $\left(\Delta \chi^{2}=281.06, \Delta d f=\right.$ $4, p<.001$ ), a four-factor model in which we combined generativity motive and perceived remaining time at work $\left(\Delta \chi^{2}=526.99, \Delta d f=4, p<.001\right)$, and a one-factor model $\left(\Delta \chi^{2}=\right.$ 2453.60, $\Delta d f=10, p<.001)$.

\section{Hypothesis Tests}


Table 4 displays the results of our hypotheses tests. In support of Hypothesis 1a and $1 \mathrm{~b}$, we found that intergenerational contact was positively associated with sense of belonging, and sense of belonging was positively associated with work engagement. As the indirect effect of intergenerational contact on work engagement via sense of belonging was positive and significant (indirect effect $=.05, S E=.02, z=2.54, p=.011,95 \%$ CI $[.010, .081]$ ), Hypothesis 1c was supported.

In support of Hypothesis 2a, we found that age was positively and significantly associated with generativity motive. However, Hypothesis $2 \mathrm{~b}$ was not supported as we did not find a significant moderation effect of generativity motive on the relation between intergenerational contact and sense of belonging. Accordingly, the indirect moderation effect of age on the relation between intergenerational contact and sense of belonging via generativity motive was not significant (indirect effect $=-.01, S E=.01, z=-0.67, p=.505$, 95\% CI $[-.018, .009])$. Thus, we did not find support for Hypothesis 2c.

Consistent with Hypothesis 3a, age was negatively associated with perceived remaining time at work. In support of Hypothesis $3 b$, we found a significant negative moderation effect of perceived remaining time at work on the relation between sense of belonging and work engagement. Finally, the indirect moderation effect of age on the relation between sense of belonging and work engagement through perceived remaining time at work was positive and significant (indirect effect $=.10, S E=.03, z=3.18, p=.001,95 \%$ CI [.036, $.153])$, supporting Hypothesis 3c.

To further illustrate the significant moderation effect, we plotted the slope of sense of belonging on work engagement at higher (i.e., more expansive; $+1 S D$ ) and lower levels (i.e., more constrained; $-1 S D$ ) of perceived remaining time at work. Figure 2 illustrates that the link between sense of belonging and work engagement is stronger for employees with more constrained perceived remaining time at work. We conducted simple slope tests to probe this moderation effect further. We found a significant positive effect of sense of belonging on 
work engagement in case of more constrained perceived remaining time at work $(\gamma=.41, S E$ $=.13, p<.001)$, and a non-significant effect in case of more expansive perceived remaining time at work $(\gamma=.12, S E=.12, p=.116)$.

\section{Supplementary Analysis}

Although not hypothesized, a question that may arise based on our findings is whether the indirect link between intergenerational contact and work engagement via sense of belonging is moderated by perceived remaining time at work. Testing this moderated mediation effect is based on combining our arguments from Hypothesis 1a regarding the positive link between intergenerational contact and sense of belonging with our arguments from Hypothesis $3 b$ regarding the moderating effect of perceived remaining time at work on the link between sense of belonging on work engagement. Accordingly, we tested the indirect effect of intergenerational contact on work engagement via sense of belonging at higher $(+1$ SD) and lower (-1 SD) levels of perceived remaining time at work. We found that the indirect effect at lower levels of perceived remaining time at work was positive (indirect effect $=0.07$, $S E=.03, z=2.74, p=.006,95 \%$ CI $[.020, .121])$, while the indirect effect at higher levels of perceived remaining time at work was non-significant (indirect effect $=0.02, S E=.02, z=$ $1.41, p=.159,95 \%$ CI $[-.008, .051])$. Further, the difference between the two conditional indirect effects was also significant $(\Delta$ indirect effect $=0.05, S E=.02, z=2.28, p=.023,95 \%$ CI $[.007, .092])$. The results of the supplementary analysis thus indicate that perceived remaining time at work is an age-related difference that shapes the motivating potential of intergenerational contact.

\section{Robustness Checks}

First, we ran the model without including the control variables (i.e., need to belong, opportunities for social interactions). The exclusion of control variables did not change our results. Second, we tested our model additionally controlling for age squared, sex, and organizational tenure on both sense of belonging and work engagement. We found that all 
effects were non-significant, and that the interpretation of the results remained unchanged. In addition, we tested a model in which we controlled for the effects of age, generativity motive, and perceived remaining time at work on intergenerational contact, to control for possible selection effects. Accordingly, older employees, employees with higher generativity motive, and employees with lower perceived remaining time at work, might be more likely to seek intergenerational contact as a form of social interaction. We found that the interpretation of the results remained unchanged when these additional control variables were included. Third, we conducted sensitivity analysis to assess the influence of missing data patterns on our results (Newman, 2014). We tested our model while only including participants who had provided data at more than one time point $(N=454)$ and at all three time points $(N=297)$. We found that the interpretation of results remained unchanged.

\section{Discussion}

The results of Study 2 suggest that intergenerational contact has motivating potential for workers, and especially for older workers. Accordingly, we found support for our argument that intergenerational contact increases work engagement because workers experience a higher sense of belonging. This motivating effect of sense of belonging was more pronounced for older workers because their perceived remaining time at work is more constrained as compared to younger workers. However, as in Study 1, our results did not support our argument that older workers compared to younger workers experience higher sense of belonging resulting from intergenerational contact because of their higher generativity motive. On the one hand, this non-significant finding could be explained by our operationalization of intergenerational contact. We asked employees to indicate how often they had conversations with coworkers from other age groups, which might have been interpreted as referring to more informal interactions only. However, the generativity motive might be particularly influential in shaping the effect of more formalized and task-related intergenerational interactions during which knowledge transfer is expected from older 
employees (Burmeister \& Deller, 2016; Kessler \& Staudinger, 2007). As older employees often see themselves as the "go-to"-people for providing knowledge to others (Burmeister, Fasbender, \& Deller, 2018), they might benefit the most in intergenerational contact that is formalized and designed to facilitate the transfer of their knowledge to younger coworkers. On the other hand, the non-significant finding in Study 2 is consistent with the non-significant finding in Study 1, suggesting that both younger and older employees may experience increased sense of belonging when engaging in intergenerational contact, and that this effect may not be shaped by the generativity motive.

\section{General Discussion}

The central aim of this research was to better understand who experiences motivational benefits from intergenerational contact, and the motivational processes by which this occurs. We developed a theoretical model that is grounded in need-based theories of work motivation and lifespan development theory to decipher why intergenerational contact motivates work engagement and to clarify the moderating role of employee age as a contact domain-specific boundary condition. We found support for a causal effect of intergenerational contact on sense of belonging, which suggests that the specific nature of intergenerational contact may be motivating. We also found that intergenerational contact had a positive indirect effect on work engagement via sense of belonging. Further, our findings indicate that age indirectly shaped the link between sense of belonging and work engagement through older workers' more constrained perceived remaining time at work. Overall, these findings suggest that intergenerational contact has motivating potential and that older compared to younger employees derive more pronounced motivational benefits from intergenerational contact due to their constrained perception of remaining time at work.

\section{Theoretical Implications}

Our findings offer several contributions to and theoretical implications for scholarship on intergroup contact, employee motivation, and workforce aging. First, we widen the 
nomological net of the intergenerational contact construct to include motivational outcomes by connecting research on intergroup contact with research on employee motivation. By linking intergenerational contact to work engagement, our findings suggest that intergenerational contact has the potential to motivate and engage both older and younger employees. We thus expand research showing that intergenerational contact can reduce negative attitudes and behavior toward age-diverse interaction partners (Abrams et al., 2006; Fasbender \& Wang, 2017; Henry et al., 2015; Iweins et al., 2013; Turner et al., 2007; Turner \& Crisp, 2010), to emphasize its motivating potential for the focal individuals involved in the intergroup interaction. In addition, we demonstrate that intergenerational contact has motivational benefits above and beyond intragenerational (and thus more general) interpersonal contact.

In addition, grounded in need-based theories of work motivation (Baumeister \& Leary, 1995; Green, Finkel et al., 2017), we introduce sense of belonging as a motivational process that explains why intergenerational contact leads to work engagement. Our findings indicate that employees feel more connected and closer to each other due to the specific nature of intergenerational contact, which, in turn, can motivate their work engagement. These findings are aligned with research on the motivating potential of workplace contact more broadly. For example, research showed that contact exposure to beneficiaries of one's work can increase motivation and performance via sense of belonging (Green, Gino, \& Staats, 2017), while social exclusion has a negative impact on sense of belonging and subsequently lowers the motivation and ability of employees to contribute to the organization (O'Reilly \& Robinson, 2009). With our research on intergenerational contact, we add an age-specific lens by showing that contact between different age groups can fulfill more basic human needs, such as the need to belong (Baumeister \& Leary, 1995). Our findings are thus aligned with research on the need-fulfilling and motivating nature of workplace contact in general (Ehrhardt \& Ragins, 2019; Fasbender et al., 2020; Green, Gino, \& Staats, 2017), but they also challenge more 
negative conceptualizations of possible conflicts in multigenerational environments (North \& Fiske, 2015; Rudolph \& Zacher, 2015). In other words, we advance research on aging at work by demonstrating that employees from other age groups can meet one's needs related to social belonging.

Second, we contribute insights into the role of employee age, as an important and contact domain-specific moderator, in shaping the effects of intergenerational contact at work. Our study thus illustrates the usefulness of connecting lifespan development theories (Baltes, 1987; Carstensen, 2006; Erikson, 1963) with research on workplace contact to uncover agerelated differences in motivational reactions to intergroup contact. Operationalizing these agerelated motivational differences in reactions to interactional processes at work using lifespan development theories (see Bohlmann et al., 2018; Wang et al., 2015) may thus support the development of more accurate predictions about the need-fulfilling potential of workplace contact (Ehrhardt \& Ragins, 2019). Our findings also advance research on the role of age at work that has primarily focused on the design of jobs and work tasks (Mühlenbrock \& Hüffmeier, 2020) by identifying more informal interpersonal interactions at work that may be particularly meaningful and motivating for younger and older employees.

In examining age differences in motivational reactions to intergenerational contact, we add to intergroup contact theory by demonstrating the value of studying contact domainspecific moderators (i.e., age, generativity motive, perceived remaining time at work) of specific intergroup contact experiences (i.e., intergenerational contact). Research to date has assumed that intergroup contact elicits universal benefits across age groups (Pettigrew et al., 2011). In addition, intergroup contact researchers have mostly studied domain-unspecific moderators such as status and social dominance orientation (Bowman \& Griffin, 2012; Kauff et al., 2016; Vedder et al., 2017). Our findings suggest that research on intergroup contact may benefit from examining contact domain-specific moderators (e.g., ethnic differences in inter-ethnic contact) to specify who benefits from specific intergroup contact experiences. 
Our findings also directly advance research on workforce aging. Accordingly, we go beyond existing research that has focused on the direct effects of age as a proxy for assumed psychological mechanisms, by theorizing and directly operationalizing the age-based mechanisms specified in lifespan development theories (Carstensen et al., 1999; Erikson, 1963). The indirect moderation effect of age through perceived remaining time at work on the link between belonging and work engagement emphasizes that age-related mechanisms based on lifespan development theories, rather than employee age per se, play an important role in understanding the ways in which age shapes motivational processes at work (Bohlmann et al., 2018; Fasbender et al., 2020). Finally, the fact that we found evidence of the moderating role of perceived remaining time at work but not generativity motive, might suggest that agingrelated perceptions of time rather than generativity motive is the more relevant psychological mechanism to explain age differences in the motivating potential of intergenerational contact.

\section{Limitations and Future Research Directions}

Our research has several limitations that need to be considered when interpreting the results. First, our research has methodological limitations. In both studies, the measure of generativity motive asked participants about the importance of teaching and training others in general, as well as sharing skills with younger people specifically (Kooij \& Van De Voorde, 2011). The age-specific item might be incongruent with our design as older and younger employees were reporting on their generativity motive and younger employees might have fewer opportunities to share knowledge and experiences with even younger coworkers. Future research should resolve this incongruency by using a different measure to capture the generativity motive. In the experimental study (Study 1), our sample size was small, which might have made the detection of the proposed moderating effect of generativity motive more difficult (Shieh, 2009). In the intragenerational contact condition, we combined younger and older dyads and thus assumed that younger and older same-age dyads operate in the same way. The task in Study 1 was a crossword puzzle. Compared to younger adults might have an 
advantage when completing this task because they tend to have more accumulated knowledge and higher verbal ability (Anderson \& Craik, 2017; Salthouse \& Somberg, 1982). Future research needs to replicate our experimental findings, using larger samples, a different randomization procedure, and a different task. In the field study (Study 2), we exclusively relied on self-report data, which might have inflated the observed relations due to common method bias. While our time-lagged design can mitigate common method bias (Podsakoff et al., 2003), and most variables in our model (i.e., generativity motive, sense of belonging, perceived remaining time at work, and work engagement) capture psychological constructs that might be difficult to assess via objective data or other report, future research could obtain data on intergenerational contact from coworkers. Such multi-source designs could further improve the methodological rigor of our research.

Second, the motivating potential inherent in intergenerational contact at work needs to be further investigated. For example, we did not capture the exact ways in which older and younger employees influence each other during intergenerational contact. Future research could use event-based sampling methods to understand which elements of intergenerational contact are most beneficial for younger and older employees. In addition, future research can further expand our findings by examining why the need-fulfilling potential of intergenerational contact compared to intragenerational contact is more pronounced. To this end, research suggests that age-based differences among coworkers may reduce the risk of unfavorable social comparisons or rivalry among coworkers (Bal \& Boehm, 2019) because people tend to compare themselves with similar rather than dissimilar others (Festinger, 1954; Kearney, 2008). Based on the pronounced age differences between generations, intergenerational interactions might be less prone to elicit these negative social comparisons processes and subsequent rivalry and conflict (Balkundi et al., 2007; Hambrick, 1994; Lawrence, 1988; Pelled et al., 1999). Future research is needed to test these possible 
differences between intergenerational and intragenerational contact and understand their effects on employee motivation.

Third, even though our research provides a novel lifespan-specific motivational lens on outcomes of intergroup contact, it only captures one mechanism (i.e., sense of belonging) to explain work engagement as a motivational outcome of intergenerational contact. It seems plausible that intergenerational contact could lead to motivational outcomes via additional mechanisms. For example, intergenerational contact might elicit emotional reactions such as pride when employees are able to share their knowledge, which, in turn, could also lead to motivational benefits. Future research should therefore expand our findings and explore additional pathways through which intergenerational contact leads to motivational benefits. In addition, research on work-related outcomes of intergroup contact for the focal individuals involved is generally scarce. Future research could investigate additional outcomes, such as positive work attitudes (e.g., job satisfaction) and work behavior (e.g., creativity, job performance). Broadening the scope of outcomes might be particularly relevant to understand which benefits younger workers can generate from intergenerational contact as our findings indicate stronger motivational benefits of intergenerational contact for older workers. Future research should thus clarify in which specific ways younger workers benefit from intergenerational contact, for example, in terms of more instrumental outcomes such as learning and career progression.

\section{Practical Implications}

Our findings have several implications for practitioners. First, as intergenerational contact can have a positive influence on employee motivation, organizations may wish to facilitate intergenerational contact to realize its motivational benefits at work. Specifically, age-diverse training groups or learning tandems (Burmeister, van der Heijden et al., 2018; Gerpott et al., 2017) could be established to create opportunities for intergenerational contact. During intergenerational contact, employees can benefit from each other's diverse 
experiences and insights while also helping each other to feel more connected at work, thereby benefitting their work engagement.

Second, our findings also showed that older employees whose perceived remaining time at work is lower benefitted more strongly from intergenerational contact compared to younger employees. As such, practitioners aiming to motivate and engage older employees may be well advised to facilitate interactions with coworkers from younger age groups. As the link between sense of belonging and work engagement was more pronounced for older workers, practitioners need to consider older employees' heightened focus on their socioemotional needs in designing their work experience. Existing research on the motivation of older employees has highlighted work features such as security and intrinsic rewards as motivating (Kooij et al., 2008), but our findings point to the relevance of social work characteristics. Creating regular opportunities for meaningful social interactions at work, for example through meetings, joint lunch breaks, and group activities, might be particularly important for motivating older employees. 


\section{References}

Aberson, C. L., \& Haag, S. C. (2007). Contact, perspective taking, and anxiety as predictors of stereotype endorsement, explicit attitudes, and implicit attitudes. Group Processes \& Intergroup Relations, 10(2), 179-201. https://doi.org/10.1177/1368430207074726

Abrams, D., Eller, A., \& Bryant, J. (2006). An age apart: The effects of intergenerational contact and stereotype threat on performance and intergroup bias. Psychology and Aging, 21(4), 691-702. https://doi.org/10.1037/0882-7974.21.4.691

Anderson, N. D., \& Craik, F. I. M. (2017). 50 years of cognitive aging theory. The Journals of Gerontology Series B: Psychological Sciences and Social Sciences, 72(1), 1-6. https://doi.org/10.1093/geronb/gbw108

Bakker, A. B., Albrecht, S. L., \& Leiter, M. P. (2011). Key questions regarding work engagement. European Journal of Work and Organizational Psychology, 20(1), 4-28. https://doi.org/10.1080/1359432X.2010.485352

Bakker, A. B., \& Bal, M. P. (2010). Weekly work engagement and performance: A study among starting teachers. Journal of Occupational and Organizational Psychology, 83(1), 189-206. https://doi.org/10.1348/096317909X402596

Bakker, A. B., \& Demerouti, E. (2007). The Job Demands-Resources model: State of the art. Journal of Managerial Psychology, 22(3), 309-328.

https://doi.org/10.1108/02683940710733115

Bakker, A. B., Schaufeli, W. B., Leiter, M. P., \& Taris, T. W. (2008). Work engagement: An emerging concept in occupational health psychology. Work \& Stress, 22(3), 187-200. https://doi.org/10.1080/02678370802393649

Bal, P. M., \& Boehm, S. A. (2019). How do I-deals influence client satisfaction? The role of exhaustion, collective commitment, and age diversity. Journal of Management, 45(4), 1461-1487. https://doi.org/10.1177/0149206317710722 
THE MOTIVATING POTENTIAL OF INTERGENERATIONAL CONTACT AT WORK 36

Balkundi, P., Kilduff, M., Barsness, Z. I., \& Michael, J. H. (2007). Demographic antecedents and performance consequences of structural holes in work teams. Journal of Organizational Behavior, 28(2), 241-260. https://doi.org/10.1002/job.428

Baltes, P. B. (1987). Theoretical propositions of life-span development psychology: On the dynamics between growth and decline. Developmental Psychology, 23, 611-626. https://doi.org/10.1037/0012-1649.23.5.611

Baumeister, R. F., \& Leary, M. R. (1995). The need to belong: Desire for interpersonal attachments as a fundamental human motivation. Psychological Bulletin, 117(3), 497-529. https://doi.org/10.1037/0033-2909.117.3.49

Becker, T. E. (2005). Potential problems in the statistical control of variables in organizational research: A qualitative analysis with recommendations. Organizational Research Methods, 8(3), 274-289. https://doi.org/10.1177/1094428105278021

Becker, T. E., Atinc, G., Breaugh, J. A., Carlson, K. D., Edwards, J. R., \& Spector, P. E. (2016). Statistical control in correlational studies: 10 essential recommendations for organizational researchers. Journal of Organizational Behavior, 37(2), 157-167. https://doi.org/10.1002/job.2053

Bernerth, J. B., \& Aguinis, H. (2016). A critical review and best-practice recommendations for control variable usage. Personnel Psychology, 69(1), 229-283. https://doi.org/10.1111/peps.12103

Boehm, S. A., Kunze, F., \& Bruch, H. (2014). Spotlight on age-diversity climate: The impact of age-inclusive HR practices on firm-level outcomes. Personnel Psychology, 67(3), 667704. https://doi.org/10.1111/peps.12047

Bohlmann, C., Rudolph, C. W., \& Zacher, H. (2018). Methodological recommendations to move research on work and aging forward. Work, Aging and Retirement, 4(3), 225-237. https://doi.org/10.1093/workar/wax023 
Bowman, N. A., \& Griffin, T. M. (2012). Secondary transfer effects of interracial contact: The moderating role of social status. Cultural Diversity and Ethnic Minority Psychology, 18(1), 35-44. https://doi.org/10.1037/a0026745

Bryk, A. S., \& Raudenbush, S. W. (1992). Hierarchical linear models. Sage.

Burmeister, A., \& Deller, J. (2016). Knowledge retention from older and retiring workers: What do we know, and where do we go from here? Work, Aging and Retirement, 2(2), 87104. https://doi.org/10.1093/workar/waw002

Burmeister, A., Fasbender, U., \& Deller, J. (2018). Being perceived as a knowledge sender or knowledge receiver: A multi-study investigation of the effect of age on knowledge transfer. Journal of Occupational and Organizational Psychology, 91(3), 518-545. https://doi.org/10.1111/joop.12208

Burmeister, A., van der Heijden, B.I.J.M., Yang, J., \& Deller, J. (2018). Knowledge transfer in age-diverse coworker dyads: How and when do age-inclusive human resource practices have an effect? Human Resource Management Journal, 28(4), 605-620. https://doi.org/10.1111/1748-8583.12207

Burmeister, A., Wang, M., \& Hirschi, A. (2020). Understanding the motivational benefits of knowledge transfer for older and younger workers in age-diverse coworker dyads: An actor-partner interdependence model. Journal of Applied Psychology, 105(7), 748-759. https://doi.org/10.1037/ap10000466

Carstensen, L. L. (2006). The influence of a sense of time on human development. Science, 312(5782), 1913-1915. https://doi.org/10.1126/science.1127488

Carstensen, L. L., Isaacowitz, D. M., \& Charles, S. T. (1999). Taking time seriously: A theory of socioemotional selectivity. American Psychologist, 54(3), 165-181. https://doi.org/10.1037//0003-066X.54.3.165 
Chiniara, M., \& Bentein, K. (2016). Linking servant leadership to individual performance: Differentiating the mediating role of autonomy, competence and relatedness need satisfaction. The Leadership Quarterly, 27(1), 124-141. https://doi.org/10.1016/j.leaqua.2015.08.004

Christian, M. S., Garza, A. S., \& Slaughter, J. E. (2011). Work engagement: A quantitative review and test of its relations with task and contextual performance. Personnel Psychology, 64(1), 89-136. https://doi.org/10.1111/j.1744-6570.2010.01203.x

Costanza, D. P., \& Finkelstein, L. M. (2015). Generationally based differences in the workplace: Is there a there there? Industrial and Organizational Psychology, 8(3), 308323. https://doi.org/10.1017/iop.2015.15

Deci, E. L., \& Ryan, R. M. (1985). Intrinsic motivation and self-determination in human behavior. Plenum.

Dovidio, J. F., Love, A., Schellhaas, F. M. H., \& Hewstone, M. (2017). Reducing intergroup bias through intergroup contact: Twenty years of progress and future directions. Group Processes \& Intergroup Relations, 20(5), 606-620. https://doi.org/10.1177/1368430217712052

Dutton, J. E., \& Ragins, B. R. (2007). Moving forward: Positive relationships at work as a research frontier. In J. E. Dutton \& B. R. Ragins (Eds.), Exploring positive relationships at work: Building a theoretical and research foundation (pp. 387-400). Routledge.

Ehrhardt, K., \& Ragins, B. R. (2019). Relational attachment at work: A complementary fit perspective on the role of relationships in organizational life. Academy of Management Journal, 62(1), 248-282. https://doi.org/10.5465/amj.2016.0245

Erikson, E. H. (1963). Childhood and society. Norton.

Fasbender, U., Burmeister, A., \& Wang, M. (2020). Motivated to be socially mindful: Explaining age differences in the effect of employees' contact quality with coworkers on 
THE MOTIVATING POTENTIAL OF INTERGENERATIONAL CONTACT AT WORK 39

their coworker support. Personnel Psychology, 73(3), 407-430.

https://doi.org/10.1111/peps.12359

Fasbender, U., \& Wang, M. (2017). Intergenerational contact and hiring decisions about older workers. Journal of Managerial Psychology, 32(3), 210-224. https://doi.org/10.1108/JMP11-2016-0339

Festinger, L. (1954). A theory of social comparison processes. Human Relations, 7, 117-140.

Finkelstein, L. M., Truxillo, D. M., Fraccaroli, F., \& Kanfer, R. (2015). An introduction to facing the challenges of a multi-age workforce: A use-inspired approach. In F. Fraccaroli, D. M. Truxillo, L. M. Finkelstein, \& R. Kanfer (Eds.), Facing the challenges of a multiage workforce: A use-inspired approach (pp. 3-22). Routledge.

Gagné, M., \& Deci, E. L. (2005). Self-determination theory and work motivation. Journal of Organizational Behavior, 26(4), 331-362. https://doi.org/10.1002/job.322

Garcia, P. R. J. M., Bordia, P., Restubog, S. L. D., \& Caines, V. (2018). Sleeping with a broken promise: The moderating role of generativity concerns in the relationship between psychological contract breach and insomnia among older workers. Journal of Organizational Behavior, 39(3), 326-338. https://doi.org/10.1002/job.2222

Gerpott, F. H., Lehmann-Willenbrock, N., \& Voelpel, S. C. (2017). A phase model of intergenerational learning in organizations. Academy of Management Learning \& Education, 16(2), 193-216. https://doi.org/10.5465/amle.2015.0185

Gielnik, M. M., Zacher, H., \& Wang, M. (2018). Age in the entrepreneurial process: The role of future time perspective and prior entrepreneurial experience. Journal of Applied Psychology. Advance online publication. https://doi.org/10.1037/apl0000322

Graham, J. W. (2009). Missing data analysis: Making it work in the real world. Annual Review of Psychology, 60, 549-576.

https://doi.org/10.1146/annurev.psych.58.110405.085530 
Grant, A. M., \& Parker, S. K. (2009). Redesigning work design theories: The rise of relational and proactive perspectives. Academy of Management Annals, 3(1), 317-375. https://doi.org/10.1080/19416520903047327

Green, P. I., Finkel, E. J., Fitzsimons, G. M., \& Gino, F. (2017). The energizing nature of work engagement: Toward a new need-based theory of work motivation. Research in Organizational Behavior, 37, 1-18. https://doi.org/10.1016/j.riob.2017.10.007

Green, P. I., Gino, F., \& Staats, B. R. (2017). Seeking to belong: How the words of internal and external beneficiaries influence performance.

Greguras, G. J., \& Diefendorff, J. M. (2009). Different fits satisfy different needs: Linking person-environment fit to employee commitment and performance using selfdetermination theory. Journal of Applied Psychology, 94(2), 465-477. https://doi.org/10.1037/a0014068

Hagerty, B. M.K., Lynch-Sauer, J., Patusky, K. L., Bouwsema, M., \& Collier, P. (1992). Sense of belonging: A vital mental health concept. Archives of Psychiatric Nursing, 6(3), 172-177. https://doi.org/10.1016/0883-9417(92)90028-H

Hagerty, B. M.K., Williams, R. A., Coyne, J. C., \& Early, M. R. (1996). Sense of belonging and indicators of social and psychological functioning. Archives of Psychiatric Nursing, 10(4), 235-244. https://doi.org/10.1016/S0883-9417(96)80029-X

Hakanen, J. J., \& Schaufeli, W. B. (2012). Do burnout and work engagement predict depressive symptoms and life satisfaction? A three-wave seven-year prospective study. Journal of Affective Disorders, 141(2-3), 415-424. https://doi.org/10.1016/j.jad.2012.02.043

Hambrick, D. C. (1994). Top management groups: A conceptual integration and reconsideration of the 'team' label. In B. M. Staw \& L. L. Cummings (Eds.), Research in organizational behavior. JAI Press. 
Harwood, J., Joyce, N., Chen, C.-Y., Paolini, S., Xiang, J., \& Rubin, M. (2017). Effects of past and present intergroup communication on perceived fit of an outgroup member and desire for future intergroup contact. Communication Research, 44(4), 530-555. https://doi.org/10.1177/0093650214565926

Heaphy, E. D., \& Dutton, J. E. (2008). Positive social interactions and the human body at work: Linking organizations and physiology. Academy of Management Review, 33(1), 137-162. https://doi.org/10.5465/amr.2008.27749365

Henry, H., Zacher, H., \& Desmette, D. (2015). Reducing age bias and turnover intentions by enhancing intergenerational contact quality in the workplace: The role of opportunities for generativity and development. Work, Aging and Retirement, 1(3), 243-253. https://doi.org/10.1093/workar/wav005

Henry, H., Zacher, H., \& Desmette, D. (2017). Future time perspective in the work context: A systematic review of quantitative studies. Frontiers in Psychology, 8, 413. https://doi.org/10.3389/fpsyg.2017.00413

Hertel, G., \& Zacher, H. (2018). Managing the aging workforce. In C. Viswesvaran, N. Anderson, D. S. Ones, \& H. K. Sinangil (Eds.), Managerial psychology and organizational approaches: Vol. 3. The SAGE handbook of industrial, work, \& organizational psychology (2nd ed., pp. 396-428). Sage.

Ilies, R., Lanaj, K., Pluut, H., \& Goh, Z. (2018). Intrapersonal and interpersonal need fulfillment at work: Differential antecedents and incremental validity in explaining job satisfaction and citizenship behavior. Journal of Vocational Behavior, 108, 151-164. https://doi.org/10.1016/j.jvb.2018.07.005

Iweins, C., Desmette, D., Yzerbyt, V., \& Stinglhamber, F. (2013). Ageism at work: The impact of intergenerational contact and organizational multi-age perspective. European 
THE MOTIVATING POTENTIAL OF INTERGENERATIONAL CONTACT AT WORK 42

Journal of Work and Organizational Psychology, 22(3), 331-346.

https://doi.org/10.1080/1359432X.2012.748656

Johnston, B. M., \& Glasford, D. E. (2017). Intergroup contact and helping: How quality contact and empathy shape outgroup helping. Group Processes \& Intergroup Relations, 136843021771177. https://doi.org/10.1177/1368430217711770

Joshi, A., Dencker, J., Franz, G., \& Martocchio, J. (2010). Unpacking generational identities in organizations. Academy of Management Review, 35(3), 392-414. https://doi.org/10.5465/AMR

Kanfer, R., \& Ackerman, P. L. (2004). Aging, adult development, and work motivation. The Academy of Management Review, 29(3), 440-458. https://doi.org/10.2307/20159053

Kanfer, R., Frese, M., \& Johnson, R. E. (2017). Motivation related to work: A century of progress. Journal of Applied Psychology, 102(3), 338-355. https://doi.org/10.1037/apl0000133

Kauff, M., Schmid, K., Lolliot, S., Al Ramiah, A., \& Hewstone, M. (2016). Intergroup contact effects via ingroup distancing among majority and minority groups: Moderation by social dominance orientation. PLOS ONE, 11(1), e0146895.

https://doi.org/10.1371/journal.pone.0146895

Kearney, E. (2008). Age differences between leader and followers as a moderator of the relationship between transformational leadership and team performance. Journal of Occupational and Organizational Psychology, 81(4), 803-811. https://doi.org/10.1348/096317907X256717

Kessler, E.-M., \& Staudinger, U. M. (2007). Intergenerational potential: Effects of social interaction between older adults and adolescents. Psychology and Aging, 22(4), 690-704. https://doi.org/10.1037/0882-7974.22.4.690 
Keyes, C.L.M. (2002). The exchange of emotional support with age and its relationship with emotional well-being. Journal of Gerontology, 57, 518-525. https://doi.org/10.1093/geronb/57.6.P518

Kilduff, M., \& Brass, D. J. (2010). Job design: A social network perspective. Journal of Organizational Behavior, 31(2-3), 309-318. https://doi.org/10.1002/job.609

King, S. B., \& Bryant, F. B. (2017). The workplace intergenerational climate scale (WICS): A self-report instrument measuring ageism in the workplace. Journal of Organizational Behavior, 38(1), 124-151. https://doi.org/10.1002/job.2118

Klein, K. J., \& Kozlowski, S. W. (Eds.). (2000). Multilevel theory, research, and methods in organizations. Jossey-Bass. https://doi.org/10.1177/109442810033001

Knight, C., Patterson, M., Dawson, J., \& Brown, J. (2017). Building and sustaining work engagement: A participatory action intervention to increase work engagement in nursing staff. European Journal of Work and Organizational Psychology, 26(5), 634-649. https://doi.org/10.1080/1359432X.2017.1336999

Kooij, D. T.A.M., De Lange, A. H., Jansen, P., \& Dikkers, J. (2008). Older workers' motivation to continue to work: Five meanings of age: A conceptual review. Journal of Managerial Psychology, 23(4), 364-394. https://doi.org/10.1108/02683940810869015

Kooij, D. T.A.M., Kanfer, R., Betts, M., \& Rudolph, C. W. (2018). Future time perspective: A systematic review and meta-analysis. Journal of Applied Psychology, 103(8), 867-893. https://doi.org/10.1037/ap10000306

Kooij, D. T.A.M., Lange, A. H. de, Jansen, P. G. W., Kanfer, R., \& Dikkers, J. S. E. (2011). Age and work-related motives: Results of a meta-analysis. Journal of Organizational Behavior, 32(2), 197-225. https://doi.org/10.1002/job.665 
Kooij, D. T.A.M., \& Van De Voorde, K. (2011). How changes in subjective general health predict future time perspective, and development and generativity motives over the lifespan. Journal of Occupational and Organizational Psychology, 84, 228-247.

Kooij, D. T.A.M., \& Zacher, H. (2016). Why and when do learning goal orientation and attitude decrease with aging? The role of perceived remaining time and work centrality. Journal of Social Issues, 72(1), 146-168. https://doi.org/10.1111/josi.12160

Kovjanic, S., Schuh, S. C., \& Jonas, K. (2013). Transformational leadership and performance: An experimental investigation of the mediating effects of basic needs satisfaction and work engagement. Journal of Occupational and Organizational Psychology, 46, n/a-n/a. https://doi.org/10.1111/joop.12022

Kunstman, J. W., Plant, E. A., Zielaskowski, K., \& LaCosse, J. (2013). Feeling in with the outgroup: Outgroup acceptance and the internalization of the motivation to respond without prejudice. Journal of Personality and Social Psychology, 105(3), 443-457. https://doi.org/10.1037/a0033082

Lang, F. R., \& Carstensen, L. L. (2002). Time counts: Future time perspective, goals, and social relationships. Psychology and Aging, 17(1), 125-139. https://doi.org/10.1037/08827974.17.1.125

Latham, G. P., \& Pinder, C. C. (2005). Work motivation theory and research at the dawn of the twenty-first century. Annual Review of Psychology, 56, 485-516. https://doi.org/10.1146/annurev.psych.55.090902.142105

Lawrence, B. S. (1988). New wrinkles in the theory of age: Demography, norms, and performance ratings. Academy of Management Journal, 31(2), 309-337. https://doi.org/10.2307/256550 
Leary, M. R., \& Kelly, K. M. (2009). Belonging motivation. In M. R. Leary \& R. H. Hoyle (Eds.), Handbook of individual differences in social behavior (pp. 400-409). Guilford Press.

Li, Y., Gong, Y., Burmeister, A., Wang, M., Alterman, V., Alonso, A., \& Robinson, S. (in press). Leveraging age diversity for organizational performance: An intellectual capital perspective. Journal of Applied Psychology. Advance online publication. https://doi.org/10.1037/apl0000497

Linz, S. J. (2004). Motivating Russian workers: Analysis of age and gender differences. The Journal of Socio-Economics, 33(3), 261-289. https://doi.org/10.1016/j.socec.2003.12.022

Little, R. J. A., \& Rubin, D. B. (2002). Statistical analysis with missing data. John Wiley \& Sons, Inc. https://doi.org/10.1002/9781119013563

Malone, G. P., Pillow, D. R., \& Osman, A. (2012). The General Belongingness Scale (GBS): Assessing achieved belongingness. Personality and Individual Differences, 52(3), 311316. https://doi.org/10.1016/j.paid.2011.10.027

McAdams, D. P., St Aubin, E. D., \& Logan, R. L. (1993). Generativity among young, midlife, and older adults. Psychology and Aging, 8(2), 221-230.

McAdams, D. P., \& St. Aubin, E. de. (1998). Generativity and adult development: How and why we care for the next generation. American Psychological Association.

Meulenaere, K. de, Boone, C., \& Buyl, T. (2016). Unraveling the impact of workforce age diversity on labor productivity: The moderating role of firm size and job security. Journal of Organizational Behavior, 37, 193-212. https://doi.org/10.1002/job.2036

Mor-Barak, M. E. (1995). The meaning of work for older adults seeking employment: The generativity factor. International Journal of Aging and Human Development, 41(4), 325344. https://doi.org/10.2190/VGTG-EPK6-Q4BH-Q67Q 
Morgeson, F. P., \& Humphrey, S. E. (2006). The work design questionnaire (WDQ): Developing and validating a comprehensive measure for assessing job design and the nature of work. Journal of Applied Psychology, 91(6), 1321-1339. https://doi.org/10.1037/0021-9010.91.6.1321

Mühlenbrock, I., \& Hüffmeier, J. (2020). Differential work design for different age groups? A systematic literature review of the moderating role of age in the relation between psychosocial work characteristics and health. Zeitschrift Für Arbeits- Und Organisationspsychologie A\&O, 64(3), 171-195. https://doi.org/10.1026/09324089/a000330

Newman, D. A. (2014). Missing data: Five practical guidelines. Organizational Research Methods, 17(4), 372-411. https://doi.org/10.1177/1094428114548590

Ng, T. W. H., \& Feldman, D. C. (2010). The relationships of age with job attitudes: A metaanalysis. Personnel Psychology, 63(3), 677-718. https://doi.org/10.1111/j.17446570.2010.01184.x

Nifadkar, S. S., \& Bauer, T. N. (2016). Breach of belongingness: Newcomer relationship conflict, information, and task-related outcomes during organizational socialization. Journal of Applied Psychology, 101(1), 1-13. https://doi.org/10.1037/ap10000035

North, M. S. (2019). A GATE to understanding “older” workers: Generation, age, tenure, experience. Academy of Management Annals. Advance online publication. https://doi.org/10.5465/annals.2017.0125

North, M. S., \& Fiske, S. T. (2015). Intergenerational resource tensions in the workplace and beyond: Individual, interpersonal, institutional, international. Research in Organizational Behavior, 35(1), 159-179. https://doi.org/10.1016/j.riob.2015.10.003 
O'Reilly, J., \& Robinson, S. L. (2009). The negative impact of ostracism on thwarted belongingness and workplace contributions. Academy of Management Proceedings(1), 17. https://doi.org/10.5465/ambpp.2009.44243707

Pelled, L. H., Eisenhardt, K. M., \& Xin, K. R. (1999). Exploring the black box: An analysis of work group diversity, conflict, and performance. Administrative Science Quarterly, 44(1), 1. https://doi.org/10.2307/2667029

Pettigrew, T. F. (1998). Intergroup contact theory. Annual Review of Psychology, 49, 65-85. https://doi.org/10.1146/annurev.psych.49.1.65

Pettigrew, T. F., \& Tropp, L. R. (2000). Does intergroup contact reduce prejudice? Recent meta-analytic findings. In S. Oskamp (Ed.), Reducing prejudice and discrimination (pp. 93-114). Erlbaum.

Pettigrew, T. F., \& Tropp, L. R. (2008). How does intergroup contact reduce prejudice? Metaanalytic tests of three mediators. European Journal of Social Psychology, 38(6), 922-934. https://doi.org/10.1002/ejsp.504

Pettigrew, T. F., Tropp, L. R., Wagner, U., \& Christ, O. (2011). Recent advances in intergroup contact theory. International Journal of Intercultural Relations, 35(3), 271-280. https://doi.org/10.1016/j.ijintrel.2011.03.001

Podsakoff, P. M., MacKenzie, S. B., Lee, J., \& Podsakoff, N. P. (2003). Common method variance in behavioral research: A critical review of the literature and recommended remedies. Journal of Applied Psychology, 88(5), 879-903. https://doi.org/10.1037/00219010.88 .5 .879

Preacher, K. J., \& Hayes, A. F. (2008). Asymptotic and resampling strategies for assessing and comparing indirect effects in multiple mediator models. Behavior Research Methods, 40(3), 879-891. https://doi.org/10.3758/BRM.40.3.879 
R Core Team. (2017). R: A language and environment for statistical computing (Version 3.4.3) [Computer software]. R Foundation for Statistical Computing. Vienna, Austria. https://www.R-project.org/

Raudenbush, S. W., \& Bryk, A. S. (2002). Hierarchical linear models: Applications and data analysis methods (2nd ed.). Sage.

Reich, T. C., \& Hershcovis, M. S. (2011). Interpersonal relationships at work. In S. Zedeck (Ed.), APA handbook of industrial and organizational psychology: Vol. 3. Maintaining, expanding, and contracting the organization (pp. 223-248). American Psychological Association. https://doi.org/10.1037/12171-006

Rich, B. L., LePine, J. A., \& Crawford, E. R. (2010). Job engagement: Antecedents and effects on job performance. Academy of Management Journal, 53(3), 617-635. https://doi.org/10.5465/AMJ.2010.51468988

Rudolph, C. W., Kooij, D. T.A.M., Rauvola, R. S., \& Zacher, H. (2018). Occupational future time perspective: A meta-analysis of antecedents and outcomes. Journal of Organizational Behavior, 39(2), 229-248. https://doi.org/10.1002/job.2264

Rudolph, C. W., Rauvola, R. S., \& Zacher, H. (2018). Leadership and generations at work: A critical review. The Leadership Quarterly, 29(1), 44-57. https://doi.org/10.1016/j.leaqua.2017.09.004

Rudolph, C. W., \& Zacher, H. (2015). Intergenerational perceptions and conflicts in multi-age and multigenerational environments. In F. Fraccaroli, D. M. Truxillo, L. M. Finkelstein, \& R. Kanfer (Eds.), Facing the challenges of a multi-age workforce: A use-inspired approach (pp. 253-282). Routledge.

Rudolph, C. W., \& Zacher, H. (2017a). Considering generations from a lifespan developmental perspective. Work, Aging and Retirement, 3(2), 113-129. https://doi.org/10.1093/workar/waw019 
Rudolph, C. W., \& Zacher, H. (2017b). The kids are alright: Taking stock of generational differences at work. The Industrial-Organizational Psychologist. Advance online publication. https://doi.org/10.31234/osf.io/wbsh5

Salthouse, T. A., \& Somberg, B. L. (1982). Skilled performance: Effects of adult age and experience on elementary processes. Journal of Experimental Psychology: General, 111(2), 176-207. https://doi.org/10.1037/0096-3445.111.2.176

Sandstrom, G. M., \& Dunn, E. W. (2014). Is Efficiency Overrated? Minimal social interactions lead to belonging and positive affect. Social Psychological and Personality Science, 5(4), 437-442. https://doi.org/10.1177/1948550613502990

Schaufeli, W. B., \& Bakker, A. B. (2003). Test manual for the Utrecht Work Engagement Scale. Utrecht University, the Netherlands, Retrieved from http://www.schaufeli.com.

Schaufeli, W. B., Bakker, A. B., \& Salanova, M. (2006). The measurement of work engagement with a short questionnaire. Educational and Psychological Measurement, 66(4), 701-716. https://doi.org/10.1177/0013164405282471

Schaufeli, W. B., Salanova, M., González-Romá, V., \& Bakker, A. B. (2002). The measurement of engagement and burnout: A two sample confirmatory factor analytic approach. Journal of Happiness Studies, 3(1), 71-92. https://doi.org/10.1023/A:1015630930326

Shieh, G. (2009). Detecting interaction effects in moderated multiple regression with continuous variables: Power and sample size considerations. Organizational Research Methods, 12(3), 510-528. https://doi.org/10.1177/1094428108320370

Shore, L. M., Cleveland, J. N., \& Sanchez, D. (2018). Inclusive workplaces: A review and model. Human Resource Management Review, 28(2), 176-189. https://doi.org/10.1016/j.hrmr.2017.07.003 
Shore, L. M., Randel, A. E., Chung, B. G., Dean, M. A., Holcombe Ehrhart, K., \& Singh, G. (2011). Inclusion and diversity in work groups: A review and model for future research. Journal of Management, 37(4), 1262-1289. https://doi.org/10.1177/0149206310385943

Shumaker, S. A., \& Brownell, A. (1984). Toward a theory of social support: Closing conceptual gaps. Journal of Social Issues, 40(4), 11-36. https://doi.org/10.1111/j.15404560.1984.tb01105.x

Tabuchi, M., \& Miura, A. (2018). Intergenerational interaction between old and young in creative task. Journal of Intergenerational Relationships, 16(3), 275-286. https://doi.org/10.1080/15350770.2018.1477421

Tempest, S. (2003). Intergenerational learning: A reciprocal knowledge development process that challenges the language of learning. Management Learning, 34(2), 181-200. https://doi.org/10.1177/1350507603034002002

Turner, R. N., \& Crisp, R. J. (2010). Imagining intergroup contact reduces implicit prejudice. British Journal of Social Psychology, 49(Pt 1), 129-142. https://doi.org/10.1348/014466609X419901

Turner, R. N., Crisp, R. J., \& Lambert, E. (2007). Imagining intergroup contact can improve intergroup attitudes. Group Processes \& Intergroup Relations, 10(4), 427-441. https://doi.org/10.1177/1368430207081533

van den Broeck, A., Vansteenkiste, M., Witte, H. de, \& Lens, W. (2008). Explaining the relationships between job characteristics, burnout, and engagement: The role of basic psychological need satisfaction. Work \& Stress, 22(3), 277-294. https://doi.org/10.1080/02678370802393672

Vedder, P., Wenink, E., \& van Geel, M. (2017). Intergroup contact and prejudice between Dutch majority and Muslim minority youth in the Netherlands. Cultural Diversity \& Ethnic Minority Psychology, 23(4), 477-485. https://doi.org/10.1037/cdp0000150 
Vondras, D. D., Pouliot, G. S., Malcore, S. A., \& Iwahashi, S. (2008). Effects of culture and age on the perceived exchange of social support resources. International Journal of Aging and Human Development, 67(1), 63-100. https://doi.org/10.2190/AG.67.1.d

Wang, M.-T., \& Eccles, J. S. (2012). Social support matters: Longitudinal effects of social support on three dimensions of school engagement from middle to high school. Child Development, 83(3), 877-895. https://doi.org/10.1111/j.1467-8624.2012.01745.x

Wang, M., Beal, D. J., Chan, D., Newman, D. A., Vancouver, J. B., \& Vandenberg, R. J. (2016). Longitudinal research: A panel discussion on conceptual issues, research design, and statistical techniques. Work, Aging and Retirement, 3(1), 1-24. https://doi.org/10.1093/workar/waw033

Wang, M., Burlacu, G., Truxillo, D. M., James, K., \& Yao, X. (2015). Age differences in feedback reactions: The roles of employee feedback orientation on social awareness and utility. Journal of Applied Psychology, 100(4), 1296-1308. https://doi.org/10.1037/a0038334

Wang, M., \& Shultz, K. S. (2010). Employee retirement: A review and recommendations for future investigation. Journal of Management, 36(1), 172-206. https://doi.org/10.1177/0149206309347957

Weiss, D., \& Lang, F. R. (2009). Thinking about my generation: Adaptive effects of a dual age identity in later adulthood. Psychology and Aging, 24(3), 729-734. https://doi.org/10.1037/a0016339

Wrzesniewski, A., Dutton, J. E., \& Debebe, G. (2003). Interpersonal sensemaking and the meaning of work. Research in Organizational Behavior, 25, 93-135. https://doi.org/10.1016/S0191-3085(03)25003-6

Xanthopoulou, D., Bakker, A. B., Demerouti, E., \& Schaufeli, W. B. (2009). Work engagement and financial returns: A diary study on the role of job and personal resources. 
THE MOTIVATING POTENTIAL OF INTERGENERATIONAL CONTACT AT WORK 52

Journal of Occupational and Organizational Psychology, 82(1), 183-200. https://doi.org/10.1348/096317908X285633

Zacher, H., \& Frese, M. (2009). Remaining time and opportunities at work: Relationships between age, work characteristics, and occupational future time perspective. Psychology and Aging, 24(2), 487-493. https://doi.org/10.1037/a0015425

Zacher, H., \& Griffin, B. (2015). Older workers' age as a moderator of the relationship between career adaptability and job satisfaction. Work, Aging and Retirement, 1(2), 227236. https://doi.org/10.1093/workar/wau009

Zacher, H., Rosing, K., Henning, T., \& Frese, M. (2011). Establishing the next generation at work: Leader generativity as a moderator of the relationships between leader age, leadermember exchange, and leadership success. Psychology and Aging, 26(1), 241-252. https://doi.org/10.1037/a0021429

Zhan, Y., Wang, M., \& Shi, J. (2015). Retirees' motivational orientations and bridge employment: Testing the moderating role of gender. Journal of Applied Psychology, 100(5), 1319-1331. https://doi.org/10.1037/a0038731 
Table 1

Study 1: Descriptive Statistics, Intercorrelations, and Cronbach's Alphas of the Study Variables

\begin{tabular}{|c|c|c|c|c|c|c|c|c|c|}
\hline Variables & $M$ & $S D$ & 1 & 2 & 3 & 4 & 5 & 6 & 7 \\
\hline 1. Dyadic gender composition ${ }^{\mathrm{a}}$ & 0.44 & 0.50 & & & & & & & \\
\hline 2. Employee age ${ }^{\mathrm{b}}$ & 3.74 & 1.42 & -.17 & & & & & & \\
\hline 3. Generativity motive & 5.23 & 1.23 & $-.23 *$ & $.27 * *$ & $(.92)$ & & & & \\
\hline 5. Intergenerational contact ${ }^{\mathrm{d}}$ & 0.33 & 0.47 & -.12 & .07 & -.11 & $-.50 * *$ & & & \\
\hline 6. Pre-intervention sense of belonging & 5.76 & 1.12 & .09 & -.13 & -.11 & -.02 & -.05 & $(.95)$ & \\
\hline
\end{tabular}

Note. $N=90 .{ }^{\text {a }} 1$ = "mixed gender dyad", $0=$ "same gender dyad"; ${ }^{\text {Rescaled by factor } 10 ; ~}{ }^{\mathrm{c}} 1=$ "intragenerational contact intervention", $0=$ "no

intragenerational contact intervention"; 1 = "intergenerational contact intervention", $0=$ "no intergenerational contact intervention".

Reliability estimates (Cronbach's alpha), where available, are displayed along the diagonal in parentheses. $* p<.05, * * p<.01$. 


\section{Table 2}

Study 1: Results of Hypotheses Testing

\begin{tabular}{|c|c|c|c|c|c|c|c|c|}
\hline & \multicolumn{4}{|c|}{ Post-intervention sense of belonging } & \multicolumn{4}{|c|}{ Generativity motive } \\
\hline & Estimate & $S E$ & $z$ & $p$ & Estimate & $S E$ & $z$ & $p$ \\
\hline Intercept & 6.02 & 0.08 & 72.77 & .000 & 0.08 & 0.12 & 0.64 & .520 \\
\hline Dyadic gender composition $^{\mathrm{a}}$ & 0.20 & 0.18 & 1.14 & .682 & & & & \\
\hline Pre-intervention sense of belonging & 0.18 & 0.09 & 2.08 & .038 & & & & \\
\hline Employee age $^{\mathrm{b}}$ & 0.13 & 0.07 & 1.90 & .058 & 0.24 & 0.09 & 2.73 & .006 \\
\hline Generativity motive & 0.19 & 0.08 & 2.31 & .021 & & & & \\
\hline Intragenerational contact ${ }^{\mathrm{c}}$ & -0.09 & 0.21 & -0.41 & .682 & & & & \\
\hline Intergenerational contact ${ }^{\mathrm{d}}$ & 0.46 & 0.21 & 2.21 & .027 & & & & \\
\hline Intergenerational contact $\mathrm{x}$ Generativity motive & 0.28 & 0.17 & 1.63 & .103 & & & & \\
\hline$R^{2}$ & & & & & & & & \\
\hline
\end{tabular}

Note. $N=90 .{ }^{\mathrm{a}} 1$ = "mixed gender dyad", 0 = "same gender dyad"; ${ }^{\mathrm{b}}$ Rescaled by factor $10 ;{ }^{\text {c }} 1=$ "intragenerational contact intervention", $0=$ "no intragenerational contact intervention"; ${ }^{\mathrm{d}} 1=$ "intergenerational contact intervention", $0=$ "no intergenerational contact intervention". 


\section{Table 3}

Study 2: Descriptive Statistics, Intercorrelations, and Cronbach's Alphas of the Study Variables

\begin{tabular}{|c|c|c|c|c|c|c|c|c|c|c|}
\hline Variables & $M$ & $S D$ & 1 & 2 & 3 & 4 & 5 & 6 & 7 & 8 \\
\hline 1. Need to belong & 4.83 & 1.14 & $(.86)$ & & & & & & & \\
\hline 2. Opportunity for social interactions & 5.03 & 1.24 & $.48^{* *}$ & $(.74)$ & & & & & & \\
\hline 3. Employee age ${ }^{a}$ & 4.67 & 1.09 & -.05 & .04 & & & & & & \\
\hline 4. Generativity motive & 5.31 & 1.25 & $.40 * *$ & $.37 * *$ & $.20 * *$ & $(.92)$ & & & & \\
\hline 5. Perceived remaining time at work & 3.29 & 1.54 & $.12 *$ & .09 & $-.67 * *$ & -.07 & $(.86)$ & & & \\
\hline 6. Intergenerational contact & 4.61 & 1.03 & $.41 * *$ & $.38 * *$ & -.05 & $.31 * *$ & .10 & $(.75)$ & & \\
\hline
\end{tabular}

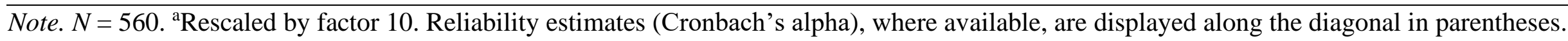

$* p<.05, * * p<.01$ 


\section{Table 4}

Study 2: Results of Hypothesis Testing

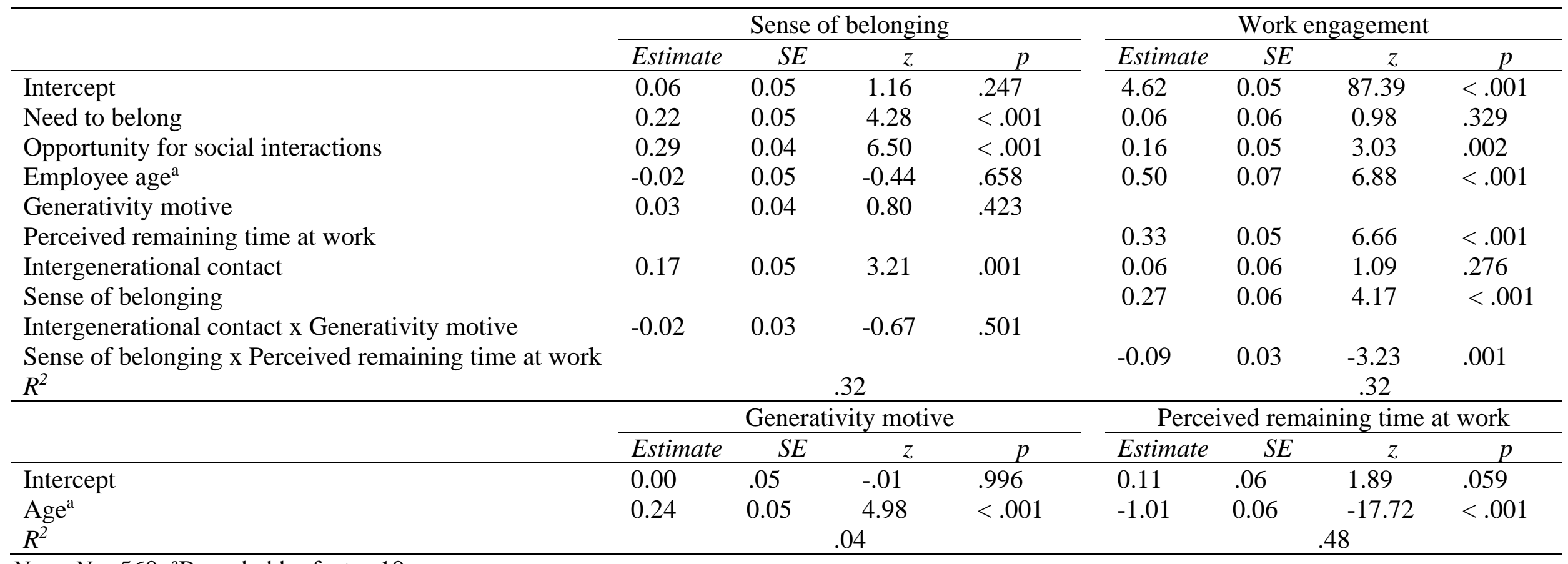

Note. $N=560 .{ }^{\text {a }}$ Rescaled by factor 10 . 


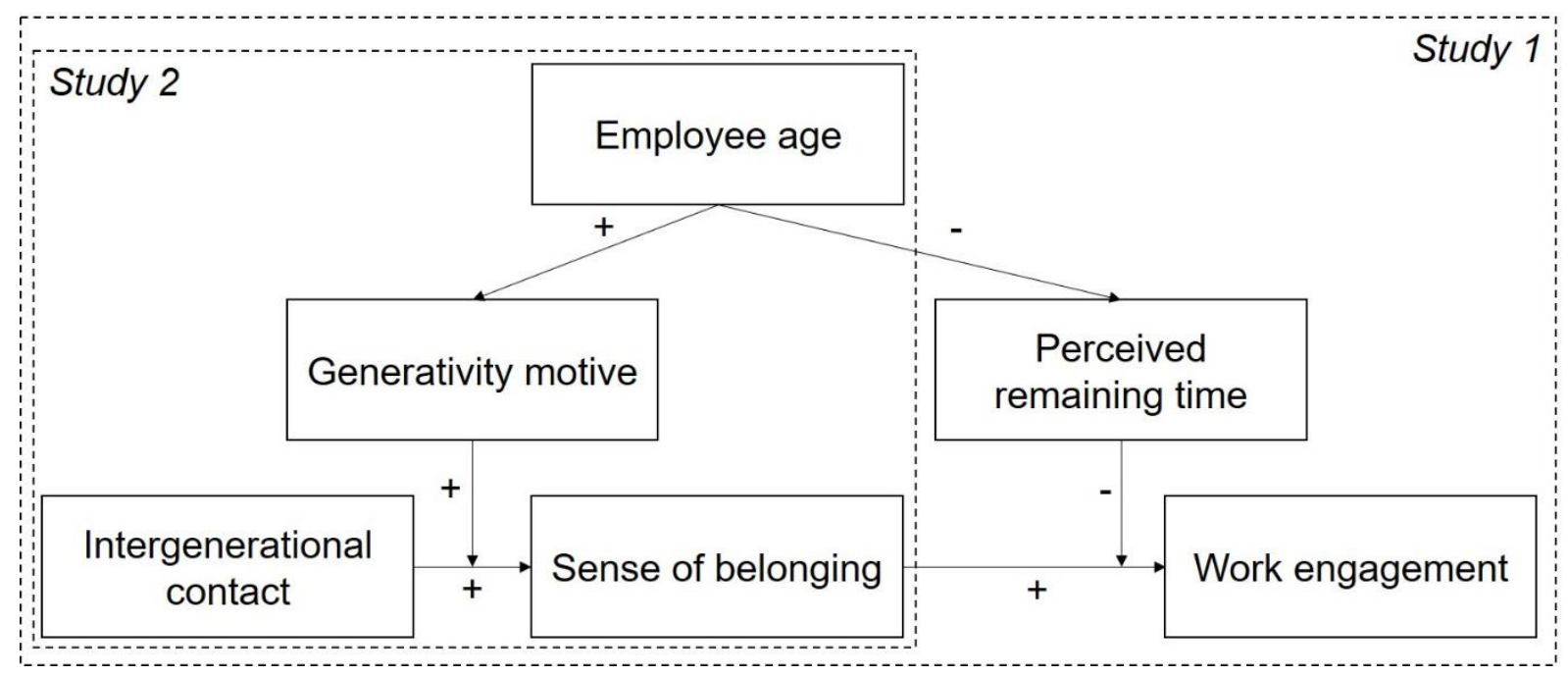

Figure 1. Conceptual Model

Note. Control variables are not displayed in the conceptual model to improve readability. In

Study 1, we controlled for dyadic gender composition. In Study 2, we controlled for need to belong and opportunities for social interaction. 


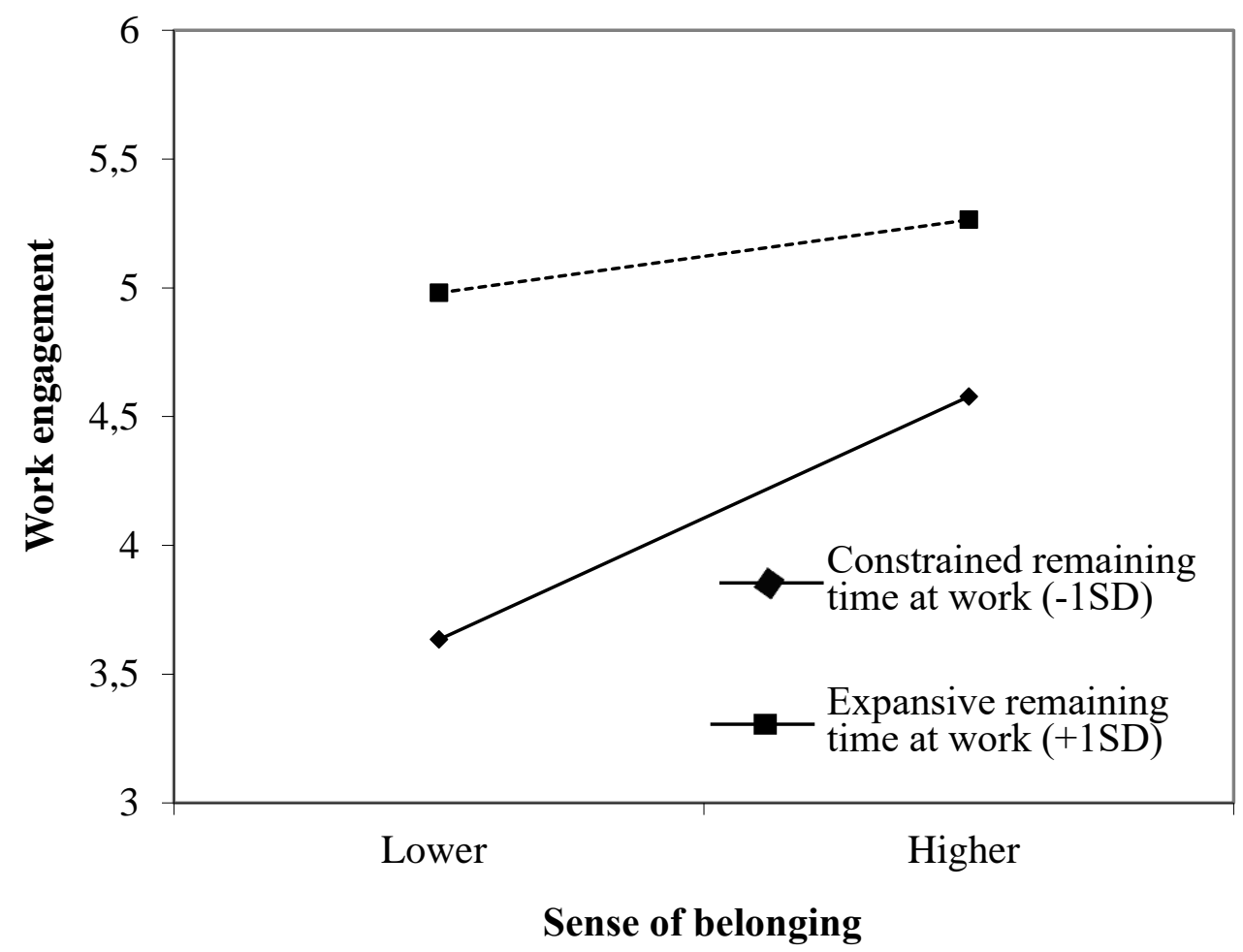

Figure 2. Study 2: Moderating Effect of Perceived Remaining Time at Work on the Relation Between Sense of Belonging and Work Engagement 